\title{
Weak influences of climate and mineral supply rates on chemical erosion rates: Measurements along two altitudinal transects in the Idaho Batholith
}

\author{
Ken L. Ferrier, ${ }^{1}$ James W. Kirchner, ${ }^{2,3,4}$ and Robert C. Finkel ${ }^{3,5}$ \\ Received 23 September 2011; revised 13 March 2012; accepted 26 March 2012; published 22 May 2012.
}

[1] Chemical weathering promotes regolith production, physical erosion, nutrient supply, and drawdown of atmospheric $\mathrm{CO}_{2}$. Although mineral dissolution rates show dependences on temperature and moisture in theoretical models and laboratory experiments, effects of climate on chemical erosion rates in nature remain uncertain, in part because variations in physical erosion rates and lithology can obscure climatic signals in chemical erosion rate measurements. Here we present new estimates of millennial-scale chemical and physical erosion rates along two altitudinal transects in the Idaho Batholith. Our measurements suggest that chemical erosion rates and the extent of regolith chemical alteration are insensitive to mean annual regolith temperature, even though the study sites span a wide range in temperatures $\left(4.8^{\circ} \mathrm{C}-10.9^{\circ} \mathrm{C}\right)$. These data also suggest that rates of chemical erosion and the extent of regolith chemical alteration are weakly correlated with the annual duration of high regolith moisture conditions. Lastly, our measurements show that the sampled regoliths tend to grow more chemically weathered with increasing regolith residence time, implying that weathering at these sites is primarily limited by mineral dissolution kinetics rather than mineral supply rates to the regolith. The lack of strong control by mineral supply means that chemical erosion rates at these sites could potentially vary in response to climatic factors. Such climatically driven variation in chemical erosion rates is not obvious in our data, however. Instead, our measurements suggest that chemical erosion rates at these sites are insensitive to mean annual regolith temperature and only weakly dependent on the length of the wet season.

Citation: Ferrier, K. L., J. W. Kirchner, and R. C. Finkel (2012), Weak influences of climate and mineral supply rates on chemical erosion rates: Measurements along two altitudinal transects in the Idaho Batholith, J. Geophys. Res., 117, F02026, doi:10.1029/2011JF002231.

\section{Introduction}

[2] Consider a fly fisherman standing in a mountain stream. Many aspects of his surroundings have been affected by chemical weathering. The soils on the adjacent hillslopes developed in part through chemical weathering of the parent

\footnotetext{
${ }^{1}$ Department of Earth, Atmospheric, and Planetary Sciences, Massachusetts Institute of Technology, Cambridge, Massachusetts, USA.

${ }^{2}$ Swiss Federal Institute for Forest, Snow, and Landscape Research, Birmensdorf, Switzerland.

${ }^{3}$ Department of Earth and Planetary Science, University of California Berkeley, Berkeley, California, USA.

${ }^{4}$ Department of Environmental Sciences, Swiss Federal Institute of Technology, Zürich, Switzerland.

${ }^{5}$ Center for Accelerator Mass Spectrometry, Lawrence Livermore National Laboratory, Livermore, California, USA.

Corresponding author: K. L. Ferrier, Department of Earth, Atmospheric, and Planetary Sciences, Massachusetts Institute of Technology, 77

Massachusetts Ave., Cambridge, MA 02139, USA. (kferrier@mit.edu)

Copyright 2012 by the American Geophysical Union.

0148-0227/12/2011JF002231
}

rock, and the trees growing in those soils derive many of their nutrients from solutes liberated by mineral dissolution. The river running down the valley axis contains weatheringderived solutes that nourish the fish he is trying to catch, and the shapes of the ridges and valleys above him have been influenced by chemical weathering through its weakening of bedrock and its acceleration of physical erosion. The temperature of the air around him has also been affected by chemical weathering. Over long timescales $\left(>10^{5}\right.$ years), chemical weathering of silicate minerals is Earth's primary sink for atmospheric $\mathrm{CO}_{2}$, and so modulates Earth's temperature via the greenhouse effect [Walker et al., 1981; Berner et al., 1983]. As such, chemical weathering is the primary cause of Earth's long-term climatic stability [Kump et al., 2000], and therefore one of the reasons that a mountain stream is a comfortable place to fish at all.

[3] Because chemical weathering is central to many important components of the Earth system - regolith development, landscape evolution, nutrient supply, and climatequantifying the controls on rates of chemical weathering is of wide interest. Although there has been considerable progress in understanding how climatic variables affect mineral 
dissolution rates in theory and in the laboratory [e.g., Brady and Carroll, 1994; Blum and Stillings, 1995; Chen and Brantley, 1997; White et al., 1999; White and Brantley, 2003], conclusions differ about the extent to which climate affects chemical weathering rates in nature. Many studies have quantified the effects of temperature on chemical weathering rates by fitting observational data to an Arrhenius function in which weathering rates are proportional to $\mathrm{e}^{E_{a} / R T}$, where $E_{a}$ is an apparent activation energy for the weathering reaction, $R$ is the universal gas constant, and $T$ is temperature. Using measurements of chemical weathering rates across a range of temperatures, it is possible to estimate a best-fit value for $E_{a}$, which reflects how strongly mineral dissolution rates depend on temperature. Values for $E_{a}$ vary from one mineral to the next [Kump et al., 2000], but there is considerable disagreement in field-derived estimates of $E_{a}$ even for individual mineral phases. For plagioclase alone, field-derived estimates of $E_{a}$ vary by more than a factor of five from 14 to $77 \mathrm{~kJ} \mathrm{~mol}^{-1}$ [Velbel, 1993; White and Blum, 1995; Riebe et al., 2004a], making it difficult to assess how strongly chemical weathering rates should depend on temperature. Recent modeling by [Lebedeva et al., 2010] suggests that accounting for reaction enthalpy in addition to $E_{a}$ may resolve some of the differences among field studies in the temperature sensitivity of mineral dissolution, but this remains to be widely tested against field measurements of mineral dissolution rates.

[4] Climate also influences chemical erosion rates through precipitation, which promotes mineral dissolution by supplying moisture to mineral surfaces in the regolith. Precipitation also promotes fluxes of water through the regolith, which reduce the concentrations of mineral dissolution products in regolith pore water and thereby drive net dissolution reactions forward. All else being equal, chemical erosion rates should increase with increasing moisture. This is broadly supported by compilations of measured chemical erosion rates that generally increase with mean annual precipitation, runoff, or water availability, albeit with considerable scatter [e.g., Bluth and Kump, 1994; Millot et al., 2002; Dupre et al., 2003; Riebe et al., 2004a; West et al., 2005; Rasmussen et al., 2011]. These compilations have been made over a series of climatically diverse sites around the globe, an approach that has the advantage of being able to exploit the widest possible range of climates. However, this approach is vulnerable to site-to-site variations in other factors that may also affect chemical erosion rates, such as lithology, physical erosion rates, vegetation, and human activity, which can confound interpretation of climate's effects on chemical erosion rates, and which may be responsible for much of the scatter in these compilations. An alternative approach is to measure chemical erosion rates at a series of sites along an altitudinal transect. Because climate changes continuously with altitude, and because altitudinal transects can lie along a single mountainside and thus within a small area, this approach is able to minimize variations in confounding variables like lithology and rock uplift rates while maximizing climatic variations. That is the approach we have taken in this study.

[5] Some prior studies along altitudinal transects have found that chemical erosion rates decrease with altitude (and hence with mean annual temperature), although the rate at which chemical erosion rates decline with altitude varies considerably among studies. [Drever and Zobrist, 1992] measured net alkalinity and silica concentrations in stream water along an altitudinal gradient extending from $220 \mathrm{~m}$ to $2400 \mathrm{~m}$ above sea level in the Swiss Alps, and found that both of these proxies for chemical weathering fluxes decreased approximately exponentially with altitude. They suggested that some of this decrease could be a consequence of the decrease in temperature with altitude, but that most of it is related to the corresponding decrease in soil thickness with altitude at these field sites. Thus they did not attribute differences in chemical weathering fluxes along this transect strictly to differences in climate, but rather to a combination of factors related to climate and mineral supply. In the Applachian Blue Ridge province, [Velbel, 1993] inferred plagioclase weathering rates from $\mathrm{Na}$ stream solute fluxes in two neighboring catchments with mean elevations of $849 \mathrm{~m}$ and $1019 \mathrm{~m}$, respectively, and found that plagioclase weathering rates were $13 \%$ faster in the lower (and hence warmer) catchment. Velbel suggested that this field setting was ideally suited for isolating the effect of temperature on chemical weathering fluxes, because the relatively small difference in altitude between these two catchments produced few differences in factors besides temperature. In an altitudinal transect extending from $2090 \mathrm{~m}$ to $2750 \mathrm{~m}$ above sea level in the Santa Rosa Mountains of Nevada, [Riebe et al., 2004b] found that the enrichment of chemically immobile $\mathrm{Zr}$ in soil relative to its parent rock decreased sharply with elevation, such that the extent of regolith chemical alteration became indistinguishable from zero at the summit. They combined these Zr-based chemical weathering intensities with denudation rates inferred from cosmogenic ${ }^{10} \mathrm{Be}$ in regolith-borne quartz to show that chemical erosion rates decreased rapidly with elevation, suggesting that changes in climate and the associated changes in vegetation can greatly affect chemical erosion rates. In contrast to these continuous declines in chemical erosion rates with elevation, a recent study along an elevation transect spanning nearly $3 \mathrm{~km}$ in altitude in California's Sierra Nevada concluded that total chemical erosion rates - calculated as the sum of chemical erosion rates in the saprolite and the overlying soil-were fastest at intermediate elevations [Dixon et al., 2009a]. Because mean annual temperature drops with elevation and mean annual precipitation increases with elevation along this transect, Dixon et al. [2009a] interpreted this pattern as a reflection of temperature-limited weathering at high altitudes and moisture-limited weathering at low altitudes.

[6] These chemical erosion rate studies are complemented by studies that have measured the extent, rather than the rate, of chemical alteration in regoliths along altitudinal transects. [Grieve et al., 1990] measured soil properties along a altitudinal transect extending from $100 \mathrm{~m}$ to $2600 \mathrm{~m}$ in altitude in Costa Rica, and found that the degree of soil chemical alteration, as inferred from soil clay content and the ratio of free to total iron, decreased systematically with elevation. [Dahlgren et al., 1997], in a study of soil development along an elevation transect extending from $198 \mathrm{~m}$ to $2865 \mathrm{~m}$ above sea level in the Sierra Nevada of California, found that two proxies for the degree of soil chemical alteration (total Fe oxide and clay contents in the soil column), were both greatest at intermediate altitudes and dropped off at higher and lower altitudes. The authors interpreted this pattern as a reflection of optimal 
weathering conditions at intermediate altitudes, with weathering at high altitudes limited by cold temperatures and weathering at low altitudes limited by a lack of moisture. They also suggested this pattern might reflect site-to-site differences in the phase of precipitation, because precipitation at the low altitude sites is dominated by rain (which may easily infiltrate into soil and thus promote chemical weathering), whereas precipitation at the high altitude sites is dominated by snow (which may lose more of its water to runoff and sublimation and thus lead to slower chemical weathering). [Bockheim et al., 2000] examined a number of stable pedons along an altitudinal transect extending from $2700 \mathrm{~m}$ to $3850 \mathrm{~m}$ in the Uinta Mountains of Utah, and found that a number of proxies for chemical weathering intensity (clay content, exchangeable cations, extractable $\mathrm{Al}$, and solum thickness) were highest at the highest elevation sites. Rather than ascribing this pattern to differences in climate, however, they suggested that this may merely reflect the older age of the high-elevation soils. [Egli et al., 2003, 2004, 2006] investigated soil properties along two altitudinal gradients extending from $950 \mathrm{~m}$ to $2440 \mathrm{~m}$ above sea level in the Italian Alps. Using the enrichment of chemically immobile $\mathrm{Ti}$ in upper soil horizons relative to a parent $\mathrm{C}$ horizon, they found that chemical losses of base cations were highest at intermediate elevations, although they found no altitudinal trends in total chemical losses. They also found that smectite concentrations were highest at intermediate elevations, and concluded that the degree of soil chemical alteration was primarily driven by the flux and availability of water. Thus some of these studies have found that the highest altitude soils are the least weathered, while others have found that the highest altitude soils are the most weathered, and yet others have concluded that the most intensely weathered soils are at intermediate altitudes.

[7] In summary, altitudinal patterns in both chemical erosion rates and the degree of soil chemical alteration differ markedly between studies, and this clouds interpretations about how climate should affect chemical erosion rates and soil development elsewhere. In this contribution, we document chemical and physical erosion rates along two altitudinal (and hence climatic) transects in the canyon of the South Fork of the Salmon River in central Idaho (Figure 1). We measured these rates using a solid-phase mass balance technique that yields co-located estimates of long-term chemical and physical erosion rates [Stallard, 1985; Riebe et al., 2001], which permits us to directly account for the potentially confounding effects of physical erosion rates and dust on chemical erosion rates. Before discussing the study sites, we first present the conceptual framework we use to estimate long-term chemical and physical erosion rates.

\section{Measuring Chemical and Physical Erosion Rates With Cosmogenic Nuclides and Elemental Abundances in Regolith, Rock, and Dust}

[8] An increasingly popular method for estimating chemical erosion rates in eroding terrain is the solid-phase mass balance method, which combines regolith production rates with rockto-regolith enrichments of chemically immobile elements within a mass balance framework. As in [Ferrier et al., 2011], here and elsewhere in this paper we use the term regolith as it is conventionally applied in the geomorphic literature, that is, as the layer of physically mobile material that overlies unweathered bedrock and saprolite. This usage is equivalent to the definition of soil in some studies [e.g., Heimsath et al., 1997] and the definition of the physically disturbed zone in [Yoo and Mudd, 2008], and it diverges from the conventional geochemical definition of regolith as all of the material between unweathered bedrock and the land surface, including layers of weathered rock and saprolite that are not physically mobile [e.g., Brantley et al., 2011]. This geochemical mass balance method, as conventionally applied, assumes that regolith thickness and composition are steady in time and that the regolith is strictly a weathering product of the local bedrock (i.e., that contributions to the regolith from atmospheric deposition are negligible) [Riebe et al., 2001, 2003, 2004b; Green et al., 2006; Yoo et al., 2007; Burke et al., 2007, 2009; Dixon et al., 2009b, 2009a]. Here we use the same method but add atmospheric dust deposition to the regolith mass balance, using the approach developed in [Ferrier et al., 2011].

[9] At its core, this is a steady state mass balance method. That is, its central assumption is that the regolith is in steady state over the regolith residence time, both in terms of its mass per unit area of hillslope and in terms of its composition. This assumption demands that the total rate of mass addition to the regolith, $P$, must be balanced by the regolith denudation rate $D$. Similarly, it demands that the influx of each element $X$ to the regolith must be balanced by physical and chemical denudation of $X$ from the regolith. This can be made more concrete by considering a hillslope regolith such as the one pictured in Figure 2. Here mass is incorporated into the regolith through two pathways: first, by regolith production from below at a rate $P_{r}$, and second, by dust deposition from above at a rate $P_{d}$. The regolith denudation rate $D$ is the sum of the mass loss rates by physical processes (e.g., biotic and aboitic creep) at a physical erosion rate $E$, and by chemical processes (e.g., mineral dissolution and downslope solute transport) at a chemical erosion rate $W$. Assuming that downslope gradients in regolith chemistry are negligible - a good approximation at hilltops and ridgelines [Mudd and Furbish, 2006; Yoo et al., 2007] - the steady state mass balance equations for the bulk regolith and for an element $X$ may be written as follows.

$$
\begin{gathered}
P=P_{r}+P_{d}=D=E+W \\
P_{X}=P_{r} X_{r}+P_{d} X_{d}=D_{X}=E X_{s}+W_{X}
\end{gathered}
$$

Here $P_{r}$ is the regolith production rate from bedrock $\left(\mathrm{M} \mathrm{L}^{-2}\right.$ $\left.\mathrm{T}^{-1}\right), P_{d}$ is the dust incorporation rate into regolith $\left(\mathrm{M} \mathrm{L}^{-2}\right.$ $\left.\mathrm{T}^{-1}\right), P$ is the total mass flux into the regolith from bedrock and dust $\left(\mathrm{M} \mathrm{L}^{-2} \mathrm{~T}^{-1}\right), P_{X}$ is the total supply rate of element $X$ to the regolith $\left(\mathrm{M} \mathrm{L}^{-2} \mathrm{~T}^{-1}\right), E$ is the physical erosion rate $\left(\mathrm{M} \mathrm{L}^{-2} \mathrm{~T}^{-1}\right), W_{X}$ is the chemical erosion rate of $X\left(\mathrm{M} \mathrm{L}^{-2}\right.$ $\mathrm{T}^{-1}$ ), and $X_{r}, X_{s}$, and $X_{d}$ are the concentrations (M/M) of $X$ in the rock, regolith, and dust, respectively.

[10] In the case of a chemically immobile element (e.g., $\mathrm{Zr}$ ), $W_{Z r}=0$ and equation (2) may be solved for the physical erosion rate $E$ (equation (3)). This expression for $E$ may be substituted into equations (1) and (2) to yield expressions for 


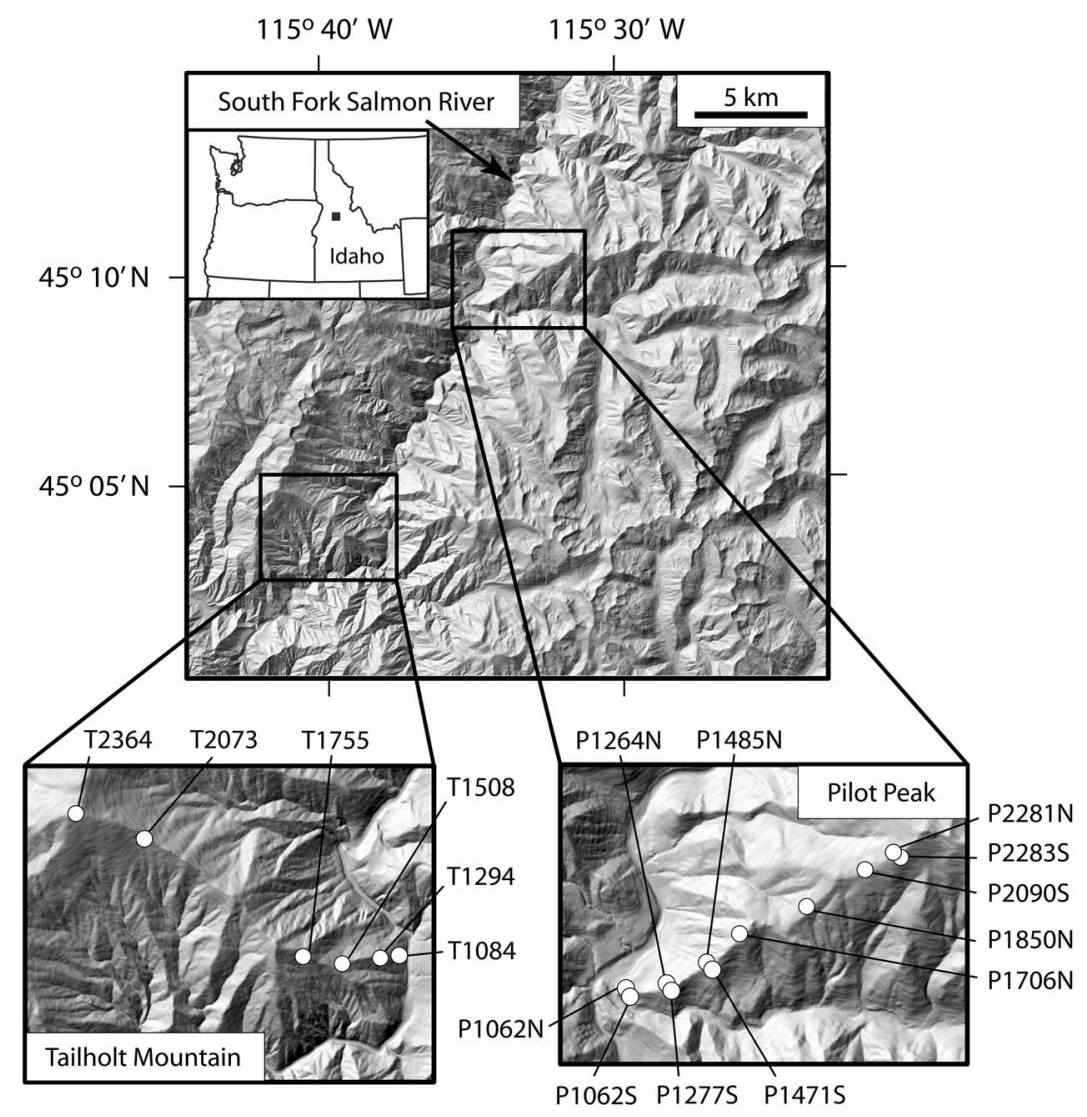

Figure 1. Field sites at Pilot Peak and Tailholt Mountain, on a shaded relief map generated from a 10-meter USGS DEM. Site identifiers (e.g., P1264N) indicate the mountain ("P" = Pilot Peak, "T" = Tailholt Mountain), altitude in meters, and, where paired samples were collected on opposite sides of a ridgeline at the same altitude, slope aspect ("N" = north, "S" = south). The black square in the inset map shows the location of the study area in Idaho.

the bulk chemical erosion rate $W$ and the elemental chemical erosion rate $W_{X}$.

$$
\begin{gathered}
E=P_{r} \frac{Z r_{r}}{Z r_{s}}+P_{d} \frac{Z r_{d}}{Z r_{s}} \\
W=P_{r}\left(1-\frac{Z r_{r}}{Z r_{s}}\right)+P_{d}\left(1-\frac{Z r_{d}}{Z r_{s}}\right) \\
W_{X}=P_{r}\left(X_{r}-X_{s} \frac{Z r_{r}}{Z r_{s}}\right)+P_{d}\left(X_{d}-X_{s} \frac{Z r_{d}}{Z r_{s}}\right)
\end{gathered}
$$

Application of this framework for estimating long-term chemical and physical erosion rates has become more common over the past decade thanks to advances in cosmogenic nuclide geochemistry, which now permit regolith production rates to be inferred from concentrations of cosmogenic nuclides within minerals in the regolith or its parent rock. Regolith production rates inferred from cosmogenic ${ }^{10} \mathrm{Be}$ in quartz, for example, have now been used in several studies to estimate long-term chemical and physical erosion rates under the assumption that dust deposition is an insignificant component of the mass balance (i.e., that $P_{d} \rightarrow 0$ ) [Riebe

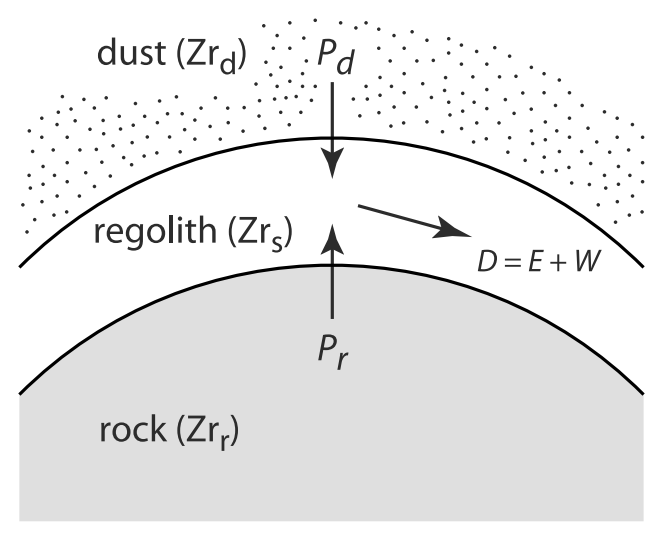

Figure 2. Conceptual mass balance model for estimating physical and chemical erosion rates on a regolith-mantled hillslope. In steady state, mass fluxes into the regolith (i.e., the sum of the regolith production rate $P_{r}$ and the dust incorporation rate $P_{d}$ ) are balanced by the denudation flux out of the regolith, $D$. If the magnitudes of $P_{r}$ and $P_{d}$ are known, concentrations of an immobile element (e.g., $\mathrm{Zr}$ ) in the bedrock, regolith, and dust can reveal the magnitudes of the physical erosion rate $E$ and chemical erosion rate $W$. 
et al., 2001, 2003, 2004b, 2004a; Green et al., 2006; Yoo et al., 2007; Burke et al., 2007, 2009; Dixon et al., 2009b, 2009a]. In places where dust fluxes are significant, equations (3)-(5) show that chemical and physical erosion rate estimates require measurements of the magnitude and the composition of the dust flux, as well as the compositions of the regolith and its parent rock. From a practical standpoint, at some field sites measurements of $P_{d}$ may not be available, and it may be difficult to estimate $P_{d}$ over the long regolith residence times relevant to these mass balance equations. Even if no measurements of dust incorporation rates are available at a given field site, however, it may be possible to use geologic considerations to pinpoint the dust source and constrain the probable dust composition. [Ferrier et al., 2011] showed that if one can constrain the dust composition, this mass balance framework may be used to estimate the magnitude of the longterm steady dust incorporation rate, provided that there are multiple immobile elements (e.g., $\mathrm{Zr}$ and $\mathrm{Ti}$ ) in the rock, regolith, and dust.

[11] Equations (4) and (5) suggest that chemical erosion rates may be closely coupled to denudation rates, a suggestion supported by many co-located measurements of physical and chemical erosion rates in the field [e.g., Stallard and Edmond, 1983; Gaillardet et al., 1999; Anderson et al., 2002; Millot et al., 2002; Riebe et al., 2004a; West et al., 2005]. Because this coupling between chemical erosion rates and denudation rates can make it difficult to discern the effects of other factors like climate on chemical erosion rates, it can be useful to normalize $W$ and $W_{X}$ by the rates at which fresh material is supplied to the regolith, to more sharply illustrate the susceptibility of the bulk regolith and individual elements to chemical losses. The fraction of the regolith denudation rate that is accounted for by chemical losses may be expressed in steady state as the ratio of $W$ to $P$, and is commonly termed the chemical depletion fraction, or CDF for short [Riebe et al., 2001].

$$
C D F=\frac{P_{r}}{P_{r}+P_{d}}\left(1-\frac{Z r_{r}}{Z r_{s}}\right)+\frac{P_{d}}{P_{r}+P_{d}}\left(1-\frac{Z r_{d}}{Z r_{s}}\right)
$$

The fraction of the elemental denudation rate that occurs by chemical processes may similarly be expressed as the ratio of the elemental chemical erosion rate $W_{X}$ to the elemental supply rate $P_{X}$, and is commonly termed $\mathrm{CDF}_{X}$ [Riebe et al., 2001].

$$
\begin{aligned}
C D F_{X}= & \frac{P_{r}}{P_{r} X_{r}+P_{d} X_{d}}\left(X_{r}-X_{s} \frac{Z r_{r}}{Z r_{s}}\right)+\frac{P_{d}}{P_{r} X_{r}+P_{d} X_{d}} \\
& \cdot\left(X_{d}-X_{s} \frac{Z r_{d}}{Z r_{s}}\right)
\end{aligned}
$$

In cases where dust fluxes are negligible (i.e., where $P_{d} \rightarrow 0$ ), these expressions for $\mathrm{CDF}$ and $\mathrm{CDF}_{X}$ converge to the expressions for $\mathrm{CDF}$ and $\mathrm{CDF}_{X}$ as defined in [Riebe et al., 2001], as they should. For comparison with the $\tau$ notation that is commonly used for describing elemental depletion relative to an immobile element [Brimhall and Dietrich, 1987; Chadwick et al., 1990], we note that in cases where dust deposition is negligible, $\mathrm{CDF}_{X}$ and $\tau_{X}$ are simply related by a negative sign: $\mathrm{CDF}_{X}=-\tau_{X}$.
[12] There are two timescales inherent in this solid-phase mass balance method. The first is the timescale associated with the accumulation of cosmogenic ${ }^{10} \mathrm{Be}$ from which regolith production rates are inferred. Because the intensity of cosmogenic radiation (and therefore the rate of ${ }^{10} \mathrm{Be}$ production) drops off rapidly below the Earth's surface, this timescale is the time the sampled quartz has spent in the short zone below the Earth's surface where it acquired the bulk of its ${ }^{10} \mathrm{Be}$. In practice, this timescale is typically calculated as the so-called cosmogenic attenuation length $(\Lambda)$ divided by the regolith production rate, where $\Lambda$ is an exponential scaling constant $\left(\Lambda=160 \mathrm{~g} \mathrm{~cm}^{-2}\right.$ [Gosse and Phillips, 2001]) that describes how quickly the intensity of cosmogenic radiation decreases as it passes through matter. For example, on a typical hillslope with a regolith production rate of $0.027 \mathrm{~g} \mathrm{~cm}^{-2} \mathrm{yr}^{-1}$ (i.e., with a lowering rate of $0.1 \mathrm{mmyr}^{-1}$ in rock with a density of $2.7 \mathrm{~g} \mathrm{~cm}^{-3}$ ), the ${ }^{10} \mathrm{Be}$ accumulation timescale is $160 \mathrm{~g} \mathrm{~cm}^{-2} / 0.027 \mathrm{~g} \mathrm{~cm}^{-2} \mathrm{yr}^{-1}=5900$ years.

[13] The second timescale inherent in this solid-phase mass balance method is the time it takes regoliths to weather to their sampled composition, which in a steady state system is the regolith residence time. This may be estimated as the regolith thickness times the regolith density divided by the rate at which mass is added to the regolith $P$. For example, in a typical hillslope regolith one meter thick, of density $1.5 \mathrm{~g}$ $\mathrm{cm}^{-3}$, and with $P=150 \mathrm{t} \mathrm{km}^{-2} \mathrm{yr}^{-1}$, the regolith residence time is 10,000 years. Thus the two timescales inherent in this solid-phase mass balance approach are often similar but not identical, and in calculating $E, W$, and $W_{X}$ it is implicitly assumed that the estimated value of the regolith production rate (which is an estimate over the timescale of cosmogenic nuclide accumulation) is also the value of the regolith production rate over the regolith residence time. Because $E, W$ and $W_{X}$ are estimated using the chemical differences between the regolith and its parent rock - a property that evolved over the regolith residence time rather than over the cosmogenic nuclide accumulation time - we suggest the appropriate timescale to apply to estimates of $E, W$, and $W_{X}$ is the regolith residence time. A full investigation of the consequences of differences between these two timescales is beyond the scope of this paper, but we note that such differences are only important to the extent that denudation rates over the cosmogenic accumulation time differ from those over the regolith residence time.

\section{Study Area: Pilot Peak and Tailholt Mountain in the Idaho Batholith}

[14] Pilot Peak and Tailholt Mountain, two mountains flanking the canyon of the South Fork of the Salmon River in the granitic Idaho Batholith (Figure 1), are the natural laboratory in which we have applied the approach in section 2 to study the effects of climate on chemical erosion rates. We selected Pilot Peak and Tailholt Mountain because they span a wide range of altitudes over short horizontal distances $-1500 \mathrm{~m}$ and $1300 \mathrm{~m}$ over 5.1 and 5.7 horizontal $\mathrm{km}$, respectively - and thus span a wide range in climates while maintaining minimal variation in other factors like rock uplift rates, lithology, and land use that could confound interpretations of measured chemical erosion rates. These mountains lie within 87-78 Ma plutons of biotite-muscovite 
Table 1. Rates of Exhumation and Denudation in the Idaho Batholith, Inferred by Diverse Methods Over Diverse Timescales

\begin{tabular}{|c|c|c|c|}
\hline $\begin{array}{l}\text { Time } \\
\text { Period }\end{array}$ & $\begin{array}{c}\text { Rate } \\
(\mathrm{mm} / \mathrm{yr})\end{array}$ & $\begin{array}{l}\text { Measurement } \\
\text { Type }\end{array}$ & Source \\
\hline $81-78 \mathrm{Ma}$ & $3.8(+1.8 /-1.4)$ & ${ }^{40} \mathrm{Ar} /{ }^{39} \mathrm{Ar}$ & $\begin{array}{l}\text { Lund et al. } \\
\text { [1986] }\end{array}$ \\
\hline 74-67 Ma & $1.0(+0.4 /-0.3)$ & ${ }^{40} \mathrm{Ar} /{ }^{39} \mathrm{Ar}$ & $\begin{array}{l}\text { Lund et al. } \\
\quad[1986]\end{array}$ \\
\hline $67-54 \mathrm{Ma}$ & $0.14(+0.4 /-0.05)$ & ${ }^{40} \mathrm{Ar} /{ }^{39} \mathrm{Ar}$ & $\begin{array}{l}\text { Lund et al. } \\
\text { [1986] }\end{array}$ \\
\hline $54 \mathrm{Ma}-$ present & 0.07 & ${ }^{40} \mathrm{Ar} /{ }^{39} \mathrm{Ar}$ & $\begin{array}{l}\text { Lund et al. } \\
\text { [1986] }\end{array}$ \\
\hline $50-10 \mathrm{Ma}$ & $0.03-0.1$ & Fission track & $\begin{array}{l}\text { Sweetkind and } \\
\quad \text { Blackwell [1989] }\end{array}$ \\
\hline $10 \mathrm{Ma}$-present & $0.32 \pm 0.10$ & Fission track & $\begin{array}{l}\text { Sweetkind and } \\
\quad \text { Blackwell [1989] }\end{array}$ \\
\hline $\begin{array}{l}\text { 4-26 } \\
\text { ka-present }\end{array}$ & $0.02-0.12$ & ${ }^{\text {Cosmogenic }}{ }^{10} \mathrm{Be}$ & This study \\
\hline $\begin{array}{l}5-26 \\
\text { ka-present }\end{array}$ & $0.02-0.12$ & $\begin{array}{l}\text { Cosmogenic } \\
{ }^{10} \mathrm{Be}\end{array}$ & $\begin{array}{l}\text { Kirchner } \\
\quad \text { et al. }[2001]\end{array}$ \\
\hline $\begin{array}{l}10-84 \\
\text { ya-present }\end{array}$ & $0.001-0.011$ & Sediment yield & $\begin{array}{l}\text { Kirchner } \\
\quad \text { et al. [2001] }\end{array}$ \\
\hline
\end{tabular}

granite and granite-granodiorite in the Idaho Batholith [Lund, 2004], and do not have mapped faults passing through them [Lund, 2004] or obvious field evidence of faulting, suggesting that neither should be subject to sharp discontinuities in rock uplift rates that could influence physical and chemical erosion rates. Vegetation is dominated by ponderosa pine and Idaho bluebunch grass at most elevations. Anthropogenic disturbance on these mountains has been minimal, with no roads or trails along the ridgelines where we established our field sites (section 4; Figure 1). Both mountains are covered with thin layers of regolith $(10-90 \mathrm{~cm})$ through which large granitic boulders $(>1 \mathrm{~m})$ crop out with a spatially variable frequency. For example, a randomly selected $10 \mathrm{~m}$ by $10 \mathrm{~m}$ patch of hillslope on Pilot Peak or Tailholt Mountain would be likely to contain no outcrops at most locations, but there are also less frequent places on the mountains where such a $10 \mathrm{~m}$ by $10 \mathrm{~m}$ patch of hillslope would consist almost entirely of outcrops. Climate records near Pilot Peak and Tailholt Mountain (Yellow Pine: http://www.wrcc.dri.edu/cgi-bin/cliMAIN. pl?id9951; Big Creek: http://www.wrcc.dri.edu/cgi-bin/ cliMAIN.pl?id0835; Warren: http://www.wrcc.dri.edu/cgibin/cliMAIN.pl?id9560; and McCall: http://www.wrcc.dri. edu/cgi-bin/cliMAIN.pl?id5708; Western Regional Climate Center, accessed March 2011) show that the region receives $63-68 \mathrm{~cm}$ of precipitation in an average year, with 57\%-66\% of it falling between October and March. The dominant form of precipitation is snow from December through February or March and rain during the remainder of the year. Midwinter months are especially wet and midsummer months are especially dry: 2.4-4.9 times more precipitation falls in December and January than in July and August. An expected moist atmospheric lapse rate of $5^{\circ} \mathrm{C}-6^{\circ} \mathrm{C} / \mathrm{km}$ implies that mean annual air temperature at the summits of Pilot Peak and Tailholt Mountain should be $8^{\circ} \mathrm{C}-9^{\circ} \mathrm{C}$ cooler than at the bases of these mountains - a difference in temperature nearly as large as the glacial-interglacial temperature shift inferred from Antarctic ice cores [Petit et al., 1999].

[15] The present-day topography of central Idaho is dominated by the drainage network of the Salmon River and its tributaries, which have incised canyons $>1 \mathrm{~km}$ deep into the Idaho Batholith. In contrast to the steep topography and high relief, the present pace of erosion in the Idaho Batholith is moderate, and has been for the past $50 \mathrm{Myr}$. The measurements stretching farthest back in time are those by [Lund et al., 1986], who used ${ }^{40} \mathrm{Ar} /{ }^{39} \mathrm{Ar}$ dating to measure mineral cooling ages approximately $50 \mathrm{~km}$ north of Tailholt Mountain. When combined with an assumed geothermal gradient of $25^{\circ} \mathrm{C} / \mathrm{km}$ [Sweetkind and Blackwell, 1989], these cooling rates imply that exhumation rates were fast $(2.4-5.6 \mathrm{~mm} / \mathrm{yr})$ shortly after emplacement of the batholith 81-78 Ma, and dropped to an average of $0.14 \mathrm{~mm} / \mathrm{yr}$ by $54 \mathrm{Ma}$ (Table 1). Complementing these ${ }^{40} \mathrm{Ar} /{ }^{39} \mathrm{Ar}$ measurements, [Sweetkind and Blackwell, 1989] interpreted fission track measurements in Idaho Batholith apatites and zircons as a reflection of slow exhumation rates $(0.03-0.1 \mathrm{~mm} / \mathrm{yr})$ from $63 \mathrm{Ma}$ to $11.4 \mathrm{Ma}$ and faster canyon incision rates $(0.32 \pm 0.10 \mathrm{~mm} / \mathrm{yr})$ since $11.4 \pm 1.4 \mathrm{Ma}$. More recently, denudation rates averaged over the past thousands to tens of thousands of years have been inferred from ${ }^{10} \mathrm{Be}$ concentrations in stream sediment elsewhere in the Idaho Batholith [Kirchner et al., 2001]. These rates range from $55 \pm 8$ to $327 \pm 42 \mathrm{t} \mathrm{km}^{-2} \mathrm{yr}^{-1}$ (which, when divided by the parent rock density, yield lowering rates of $0.02 \pm 0.003 \mathrm{~mm} / \mathrm{yr}$ to $0.12 \pm 0.02 \mathrm{~mm} / \mathrm{yr}$ ), and are, on average, 17 times faster than short-term fluvial sediment fluxes measured in the same rivers over the previous $10-84$ years.

[16] As a group, these studies suggest that erosion in the Idaho Batholith is highly episodic on short timescales, with very slow erosion for centuries to millennia punctuated by large, infrequent erosional events. When averaged over millennial or longer timescales, the Idaho Batholith has been eroding at $0.02-0.32 \mathrm{~mm} / \mathrm{yr}$ - comparable to the modern-day globally averaged denudation rate of approximately $0.05 \mathrm{~mm} /$ yr [Wilkinson and McElroy, 2007] - for the past $50 \mathrm{Myr}$ (Table 1). The long-term rates reported in these studies provide a context for our measurements of regolith production rates (section 5.1), which are averaged over the past thousands to tens of thousands of years.

\section{Methods}

\subsection{Field Sampling of Rocks and Regoliths}

[17] In September 2005 we established a series of field sites on Pilot Peak and Tailholt Mountain to measure chemical erosion rates along two altitudinal (and hence climatic) ridgeline transects (Figure 1; Table 2). With the exception of site P2283S, which is located in a grove of ponderosa pine, the dominant vegetation at all of the study sites is Idaho bluebunch grass. The trees at site P2283S have a mean spacing of 4-5 meters and provide significant shade to the underlying regolith. By contrast, the regoliths at the other study sites are broadly exposed to solar radiation; the bunch grasses that dominate the vegetation at these sites are 20-40 cm tall and provide minimal shade.

[18] Because practical application of the mass balance approach requires estimates of the mean compositions of regolith and its parent rock, we collected groups of regolith and rock samples at each field site to constrain their mean compositions and their compositional uncertainties. At each site we collected two sets of regolith samples, the first of which consisted of 16 regolith samples collected from a 
Table 2. Field Site Characteristics

\begin{tabular}{|c|c|c|c|c|c|c|c|c|c|}
\hline Site & $\begin{array}{l}\text { Latitude } \\
\left({ }^{\circ} \mathrm{N}\right)\end{array}$ & $\begin{array}{l}\text { Longitude } \\
\left({ }^{\circ} \mathrm{W}\right)\end{array}$ & $\begin{array}{l}\text { Altitude } \\
\text { (m) }\end{array}$ & $\begin{array}{l}\text { Regolith } H \\
(\mathrm{~cm})(n)^{\mathrm{a}}\end{array}$ & $\begin{array}{l}\text { Distance to Ridge } \\
(\mathrm{m})^{\mathrm{b}}\end{array}$ & $\begin{array}{l}\text { Slope } \\
\left({ }^{\circ}\right)\end{array}$ & $\begin{array}{l}\text { MART } \\
\left({ }^{\circ} \mathrm{C}\right)^{\mathrm{c}}\end{array}$ & $\begin{array}{l}\text { Moisture } \\
\text { Index }^{\mathrm{d}}\end{array}$ & Aspect \\
\hline \multicolumn{10}{|c|}{ Pilot Peak } \\
\hline P2283S & $45^{\circ} 10.263^{\prime}$ & $115^{\circ} 31.869^{\prime}$ & 2283 & $50 \pm 4(11)$ & $43-48$ & $20-25$ & 4.8 & 0.74 & $\mathrm{~S}$ \\
\hline P2281N & $45^{\circ} 10.270^{\prime}$ & $115^{\circ} 31.895^{\prime}$ & 2281 & $16 \pm 6(7)$ & $30-40$ & $20-30$ & 5.0 & 0.73 & W \\
\hline P2090S & $45^{\circ} 10.156^{\prime}$ & $115^{\circ} 32.234^{\prime}$ & 2090 & $57 \pm 5(7)$ & $40-46$ & $15-20$ & 7.1 & 0.69 & SW \\
\hline P1850N & $45^{\circ} 09.867^{\prime}$ & $115^{\circ} 32.882^{\prime}$ & 1850 & $29 \pm 5(13)$ & $2-9$ & 25 & 5.1 & 0.79 & W \\
\hline $\mathrm{P} 1706 \mathrm{~N}$ & $45^{\circ} 09.675^{\prime}$ & $115^{\circ} 33.620^{\prime}$ & 1706 & $38 \pm 3(14)$ & $10-16$ & $20-26$ & 7.6 & 0.57 & W \\
\hline P1485N & $45^{\circ} 09.438^{\prime}$ & $115^{\circ} 33.960^{\prime}$ & 1485 & $31 \pm 2(16)$ & $21-27$ & $23-26$ & 7.6 & 0.60 & W \\
\hline P1471S & $45^{\circ} 09.419^{\prime}$ & $115^{\circ} 33.960^{\prime}$ & 1471 & $32 \pm 3(15)$ & $24-30$ & 26 & 10.9 & 0.58 & SW \\
\hline P1277S & $45^{\circ} 09.259^{\prime}$ & $115^{\circ} 34.403^{\prime}$ & 1277 & $44 \pm 2(21)$ & $17-26$ & $25-35$ & 9.8 & 0.56 & SW \\
\hline P1264N & $45^{\circ} 09.276^{\prime}$ & $115^{\circ} 34.406^{\prime}$ & 1264 & $43 \pm 3(20)$ & $9-18$ & 33 & 7.4 & 0.52 & NW \\
\hline P1062S & $45^{\circ} 09.228^{\prime}$ & $115^{\circ} 34.924^{\prime}$ & 1062 & $>75(1)$ & $2-7$ & $10-20$ & 9.0 & 0.59 & SW \\
\hline P1062N & $45^{\circ} 09.238^{\prime}$ & $115^{\circ} 34.949^{\prime}$ & 1062 & $33 \pm 2(19)$ & $2-6$ & $23-30$ & 7.9 & 0.63 & $\mathrm{~N}$ \\
\hline \multicolumn{10}{|c|}{ Tailholt Mt. } \\
\hline T2364 & $45^{\circ} 04.867^{\prime}$ & $115^{\circ} 41.654^{\prime}$ & 2364 & $28 \pm 2(10)$ & $27-36$ & $11-16$ & 6.1 & 0.77 & SE \\
\hline T2073 & $45^{\circ} 04.657^{\prime}$ & $115^{\circ} 40.896^{\prime}$ & 2073 & $25 \pm 3(7)$ & $0-5$ & 9 & 6.9 & 0.72 & E \\
\hline T1755 & $45^{\circ} 03.688^{\prime}$ & $115^{\circ} 39.095^{\prime}$ & 1755 & $37 \pm 4(13)$ & $5-11$ & $22-27$ & 8.2 & 0.53 & $\mathrm{NE}$ \\
\hline T1508 & $45^{\circ} 03.632^{\prime}$ & $115^{\circ} 38.651^{\prime}$ & 1508 & $32 \pm 4(16)$ & $1-8$ & 30 & 7.7 & 0.51 & $\mathrm{~N}$ \\
\hline T1294 & $45^{\circ} 03.674^{\prime}$ & $115^{\circ} 38.226^{\prime}$ & 1294 & $57 \pm 4(15)$ & $55-60$ & 24-39 & $7.7^{\mathrm{e}}$ & no data & E \\
\hline T1084 & $45^{\circ} 03.682^{\prime}$ & $115^{\circ} 38.016^{\prime}$ & 1084 & $56 \pm 4(12)$ & 400 & $35-40$ & 9.1 & 0.52 & $\mathrm{E}$ \\
\hline
\end{tabular}

${ }^{a}$ Regolith thickness $H$ (mean \pm standard error (SE)), from $n$ measurements) is the vertical distance between the parent material and the hillslope surface.

${ }^{\mathrm{b}}$ Distances are along the hillslope from the regolith sampling plot to the ridge in the direction of steepest ascent.

${ }^{c}$ Mean annual regolith temperatures (MART) are averages over 8/1/2006-7/31/2008 on Pilot Peak and over 10/1/2005-9/30/2006 on Tailholt Mountain. These ranges were chosen to include as many complete climate records as possible. Some MART values were calculated with the help of interpolations to fill gaps in time series; see section S6 in the auxiliary materials.

${ }^{\mathrm{d}}$ We define the moisture index as the fraction of the year the regolith is "wet," a state we define as wetter than an arbitrary moisture threshold (Figure 4).

${ }^{\text {e}}$ Because the instruments at site T1294 did not record good data during the first year of monitoring, T1294's MART is reported here as $1.45^{\circ} \mathrm{C}$ cooler than the nearest site, T1084, as was the case from 11/1/2006-10/31/2007 when instruments at both T1294 and T1084 recorded good data.

small rectangular plot $(\sim 10 \mathrm{~m} \times 10 \mathrm{~m})$. This small horizontal spread in regolith sample locations was intended to quantify horizontal variability in regolith composition and accurately constrain mean regolith composition. For consistency's sake, each of these 16 regolith samples was collected $10-15 \mathrm{~cm}$ below the surface, which roughly corresponded to the base of the roots of the bunch grasses. These are the samples from which mean regolith composition at each site was calculated (section 5.2). Regolith sampling plots were sited close to ridgelines to minimize variations in regolith chemistry that can occur during downslope regolith transport [e.g., Green et al., 2006; Yoo et al., 2007]. With the exception of site T1084, which lies at the base of a roughly planar hillslope $400 \mathrm{~m}$ below the nearest ridgeline, all field sites were $0-60 \mathrm{~m}$ from the ridgeline in the direction of steepest ascent (Table 2). Within the regolith sampling plot at each field site, one pit was dug down to or close to the parent material to install temperature and moisture probes. In each regolith pit, we collected a second set of regolith samples from a range of depths to quantify vertical variability in composition. Where possible, these included samples of the parent material below the regolith. In subsequent field trips, we dug numerous pits down to parent material within the regolith sampling areas to estimate regolith thickness, which among sites averaged $40 \mathrm{~cm}$ and ranged from $16 \mathrm{~cm}$ to $>75 \mathrm{~cm}$ (Table 2).

[19] At most field sites, the parent material was a continuous layer of weathered rock, although at a few sites the parent material consisted of a layer of contiguous angular rock fragments $>30 \mathrm{~cm}$ in diameter with narrow subparallel gaps $(<1 \mathrm{~cm})$ between them, suggestive of a layer of fractured rock. In addition to the regolith samples, 40 rock samples were chipped from the outer $5-10 \mathrm{~cm}$ of extant rock outcrops to characterize the parent material of the regolith. This approach implicitly assumes that the composition of the rock outcrops is representative of the composition of the parent rock underlying the regolith [e.g., Riebe et al., 2004a]. At each field site, we collected 40 rock outcrop samples to characterize the parent material of the regolith. Most rock samples were collected within $10 \mathrm{~m}$ up-slope of the regolith plots. At some sites, there were few outcrops immediately next to the regolith plots, and at these sites outcrops were sampled on the ridge as much as $\sim 50 \mathrm{~m}$ from the regolith plots. At four elevations on Pilot Peak, we collected regolith samples from both sides of the ridge to examine the effects of slope aspect on regolith climate and chemical erosion rates. These paired sites are sites P2283S and P2281N, P1471S and $\mathrm{P} 1485 \mathrm{~N}, \mathrm{P} 1277 \mathrm{~S}$ and $\mathrm{P} 1264 \mathrm{~N}$, and $\mathrm{P} 1062 \mathrm{~S}$ and $\mathrm{P} 1062 \mathrm{~N}$ (Table 2). In this naming convention, the site ID indicates the mountain (P for Pilot Peak, $\mathrm{T}$ for Tailholt Mountain), the altitude in meters, and, where regoliths were sampled on both sides of the ridgeline, the slope aspect. Thus site P1062S, for example, is a south-facing site on Pilot Peak at $1062 \mathrm{~m}$. We consider rock samples collected from the ridgeline between these paired sites to be representative of the parent rock underlying the regoliths on both sides of the ridge.

\subsection{Installation of Moisture and Temperature Probes}

[20] In September 2005 we installed soil moisture probes and temperature probes in the uphill face of the regolith pit at each field site. Each site was instrumented with three Decagon ECH2O-10 soil moisture probes and two Decagon temperature probes, which were connected to a single Decagon Em-5 datalogger housed in an airtight metal canister. At sites where 
Table 3. Cosmogenic ${ }^{10} \mathrm{Be}$ Concentrations and CRONUS-Inferred Regolith Production Rates (Mean $\pm \mathrm{SE})^{\mathrm{a}}$

\begin{tabular}{|c|c|c|c|}
\hline $\begin{array}{l}\text { Site } \\
\text { Name }\end{array}$ & $\begin{array}{l}\text { Topographic } \\
\text { Shielding }\end{array}$ & $\begin{array}{c}{\left[{ }^{\left[{ }^{10} \mathrm{Be}\right]}\right.} \\
\left(10^{4} \text { atoms } / \mathrm{g}\right)\end{array}$ & $\begin{array}{l}\text { Regolith Production } \\
\text { Rate }\left(\mathrm{t} \mathrm{km}^{-2} \mathrm{yr}^{-1}\right)\end{array}$ \\
\hline \multicolumn{4}{|c|}{ Pilot Peak } \\
\hline P2283S & 0.989 & $28.7 \pm 0.7$ & $167 \pm 14$ \\
\hline P2281N & 0.996 & $26.3 \pm 0.7$ & $183 \pm 15$ \\
\hline P2090S & 0.996 & $28.3 \pm 0.6$ & $150 \pm 12$ \\
\hline P1850N & 0.988 & $18.8 \pm 0.4$ & $194 \pm 15$ \\
\hline $\mathrm{P} 1706 \mathrm{~N}$ & 0.991 & $20.0 \pm 0.5$ & $166 \pm 13$ \\
\hline P1485N & 0.989 & $31.0 \pm 0.6$ & $91 \pm 7$ \\
\hline P1471S & 0.987 & $29.8 \pm 0.7$ & $94 \pm 7$ \\
\hline P1277S & 0.967 & $14.4 \pm 0.3$ & $171 \pm 13$ \\
\hline P1264N & 0.977 & $15.5 \pm 0.4$ & $159 \pm 12$ \\
\hline P1062S & 0.992 & $29.8 \pm 0.7$ & $71 \pm 5$ \\
\hline P1062N & 0.975 & $37.6 \pm 1.0$ & $55 \pm 4$ \\
\hline \multicolumn{4}{|c|}{ Tailholt Mountain } \\
\hline T2364 & 0.999 & $34.9 \pm 1.2$ & $145 \pm 12$ \\
\hline T2073 & 0.998 & $19.6 \pm 0.5$ & $217 \pm 17$ \\
\hline T1755 & 0.985 & $10.8 \pm 0.2$ & $320 \pm 24$ \\
\hline T1508 & 0.978 & $11.8 \pm 0.2$ & $248 \pm 19$ \\
\hline T1294 & 0.952 & $9.1 \pm 0.2$ & $275 \pm 21$ \\
\hline T1084 & 0.935 & $8.8 \pm 0.2$ & $243 \pm 18$ \\
\hline
\end{tabular}

${ }^{\mathrm{a}}$ Regolith production rates were calculated with the Lal/Stone production rate scaling scheme in version 2.2 of the CRONUS-Earth online denudation rate calculator [Balco et al., 2008], under the steady state assumption that regolith production rates equal denudation rates. Inputs to the CRONUS calculator for latitude, longitude, and altitude were taken from Table 2, and other inputs were assumed to be: sample thickness $0 \mathrm{~cm}$, paren material density $2.7 \mathrm{~g} \mathrm{~cm}^{-3}$, and the standard atmospheric scaling. ${ }^{10} \mathrm{Be}$ concentrations were measured at LLNL-CAMS on 15 July 2007 and referenced to isotopic standard 07KNSTD3110.

${ }^{\mathrm{b}}$ Topographic shielding factors were calculated with the CRONUS calculator using eight horizon shielding angles measured in the field at azimuths of $0,45,90,135,180,225,270$, and 315 degrees.

the regolith pits were deep enough to reach parent material (all sites except P1062S, T1084, and T1508), one temperature probe and one soil moisture probe were placed at the boundary between regolith and its parent material. A second soil moisture probe was inserted into the regolith at a depth of $5 \mathrm{~cm}$, and the third soil moisture probe was placed at an intermediate depth between the upper and lower probes. The second temperature probe was originally placed such that its tip emerged just above the regolith surface, and was covered with an opaque perforated plastic box $6 \mathrm{~cm} \times$ $10 \mathrm{~cm} \times 7 \mathrm{~cm}$ in size to shield it from direct sunlight. This was done with the intention of measuring air temperature. These upper temperature probes did not produce good data during the first year of monitoring - some probes failed during hot temperature excursions, and some were bitten off by wildlife - so during our return to these sites in 2006, these upper temperature probes were buried at a depth of $5 \mathrm{~cm}$. All instruments recorded one reading every four hours, providing a coarse picture of diurnal variations in regolith climates and a detailed picture of longer-period variations in regolith climates.

\subsection{Sample Preparation for Chemical Analysis of Rock and Regolith}

[21] All rock and regolith samples were prepared for chemical analysis by X-ray fluorescence by standard procedures [Riebe, 2000]. Each sample was split, and about $30 \mathrm{~g}$ of one of the splits was powdered in a tungsten carbide Spex shatterbox. As demanded by the geochemical mass balance, we measured the composition of the bulk regolith including rock fragments, not merely the fine fraction. Powdered samples were then baked at $500^{\circ} \mathrm{C}$ for 12 hours to eliminate organic material. At this point, two sets of samples were prepared, one for major element chemistry and one for trace element chemistry. Major element samples were prepared by mixing $3.5000 \pm 0.0001 \mathrm{~g}$ of lithium tetraborate with $0.5000 \pm 0.0001 \mathrm{~g}$ of powdered sample, homogenizing this powder in a shaker for 15 minutes, melting the mixed powders in a platinum crucible above a bunsen burner flame for 10 minutes, and pouring the melted mixture into a platinum tray. This yielded glass disks roughly $33 \mathrm{~mm}$ in diameter and $2 \mathrm{~mm}$ thick. Trace element samples were prepared by mixing $3.3 \pm 0.1 \mathrm{~g}$ of powdered sample with five drops of polyvinyl alcohol and pressing the mixed powder into a pellet with a boric acid backing. Both trace element pellets and major element disks were then analyzed for elemental abundances on a Phillips 2400R X-ray fluorescence spectrometer.

\subsection{Sample Preparation for Analysis of Cosmogenic ${ }^{10} \mathrm{Be}$}

[22] Regolith production rates were inferred from concentrations of ${ }^{10} \mathrm{Be}$ in quartz extracted from amalgamated regolith samples at each site. From each of the sixteen nearsurface regolith samples (i.e., those collected at a depth of $10-15 \mathrm{~cm}$ ) at each site, we split approximately $150 \mathrm{~g}$ of regolith, and mixed these splits together. These amalgamated regolith samples were themselves split, and from one of these splits $39-55 \mathrm{~g}$ of quartz was isolated from the $>250$ micron size fraction by standard magnetic and chemical separations [Kohl and Nishiizumi, 1992; Riebe, 2000]. These quartz samples were spiked with known amounts of ${ }^{9} \mathrm{Be}$ in solution, after which they were dissolved in a mixture of hydrofluoric and nitric acids, dried down in platinum crucibles, redissolved in sulfuric acid, dried down a second time, and redissolved in hydrochloric acid. Beryllium was then isolated from other elements in cation exchange columns and precipitated as beryllium hydroxide by raising the $\mathrm{pH}$ of the solution to 8 with ammonium hydroxide. Beryllium hydroxide was isolated from solution by centrifugation, placed in quartz crucibles, and baked at $750^{\circ} \mathrm{C}$ to oxidize the material to $\mathrm{BeO}$. Each $\mathrm{BeO}$ sample was then mixed with niobium powder and packed into stainless steel sample holders. Concentrations of ${ }^{10} \mathrm{Be}$ in these $\mathrm{BeO}$ samples were measured at the Center for Accelerator Mass Spectrometry at Lawrence Livermore National Laboratory on July 15, 2007 and referenced to isotopic standard 07KNSTD3110. We used these ${ }^{10} \mathrm{Be}$ concentrations to calculate each site's denudation rate (which under the steady state regolith assumption is equivalent to the regolith production rate) with the CRONUS calculator [Balco et al., 2008], a tool designed to standardize calculation of cosmogenically-inferred denudation rates. Reported regolith production rates in Table 3 were calculated with CRONUS-Earth version 2.2 and the Lal/Stone production rate scaling. Inputs to CRONUS for sample latitude, longitude, and elevation are listed in Table 2, and all other inputs are listed in Table 3. Shielding factors were calculated in CRONUS using eight horizon angles measured at each 


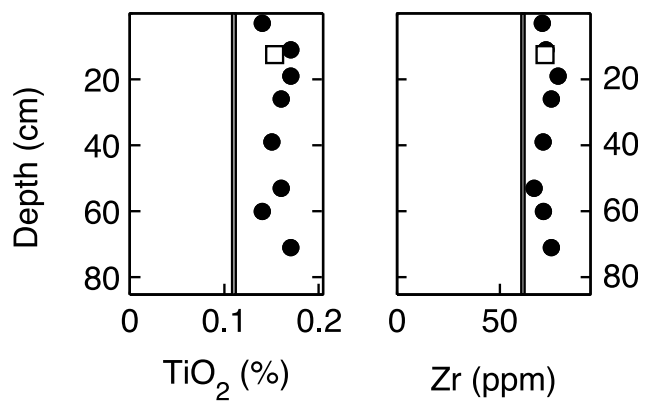

Figure 3. Concentrations of $\mathrm{Zr}$ and $\mathrm{Ti}$ in a vertical regolith profile at site T1084. Solid circles represent regolith samples; the vertical gray box represents the average rock outcrop composition (mean and SE); and the open square represents the average composition of the 16 regolith samples collected at $10-15 \mathrm{~cm}$ depth elsewhere at this site. The absence of systematic vertical trends in $\mathrm{Zr}$ and $\mathrm{Ti}$ at this site and others (Figures S1-S17) suggests that the sampled regoliths have been vertically mixed over the regolith residence time.

field site with a Brunton compass at azimuths of 0, 45, 90, $135,180,225,270$, and 315 degrees (Table 3).

\section{Data}

\subsection{Regolith Production Rates Inferred From Cosmogenic ${ }^{10} \mathrm{Be}$}

[23] CRONUS-calculated regolith production rates at our field sites range from 55 to $320 \mathrm{t} \mathrm{km}^{-2} \mathrm{yr}^{-1}$, which can be divided by the parent rock density (assumed to be $2.7 \mathrm{~g}$ $\mathrm{cm}^{-3}$ ) to yield lowering rates of 0.02 to $0.12 \mathrm{~mm} \mathrm{yr}^{-1}$ (Table 3). Regolith production rates on Tailholt Mountain tend to be faster than those on Pilot Peak (Figure 5). On Pilot Peak regolith production rates range from 55 to $194 \mathrm{t} \mathrm{km}^{-2}$ $\mathrm{yr}^{-1}$, while on Tailholt Mountain regolith production rates range from 217 to $320 \mathrm{t} \mathrm{km}^{-2} \mathrm{yr}^{-1}$ except at the summit (site $\mathrm{T} 2364$ ), where the regolith production rate is $145 \mathrm{t} \mathrm{km}^{-2}$ $\mathrm{yr}^{-1}$ (Table 3). These regolith production rates are comparable to other regolith production rates inferred from cosmogenic ${ }^{10} \mathrm{Be}$ in the Idaho Batholith [Kirchner et al., 2001], approximately an order of magnitude faster than physical erosion rates inferred from short-term sediment yields over the past 10-84 years [Kirchner et al., 2001], and over an order of magnitude slower than exhumation rates in the period following emplacement of the batholith approximately $80 \mathrm{Ma}$ [Lund et al., 1986].

\subsection{Chemical Composition of Rock and Regolith}

[24] Tables S1-S6 in the auxiliary materials list the chemical composition of the 916 rock and regolith samples from our field sites on Pilot Peak and Tailholt Mountain and the average rock and regolith compositions at each site. ${ }^{1}$ The average regolith compositions include only the sixteen horizontally distributed regolith samples collected $10-15 \mathrm{~cm}$ below the surface and do not include the regolith samples collected from the vertical regolith profile at each site,

${ }^{1}$ Auxiliary materials are available in the HTML. doi:10.1029/ 2011JF002231. because regolith samples at depth may be below the zone of thorough regolith mixing and thus may not have a composition that is representative of the regolith that is actively eroding, which is what the mass balance framework in equations (1)-(7) requires.

[25] At 15 of the 17 field sites on Pilot Peak and Tailholt Mountain, the sets of rock and regolith samples are well approximated by multivariate normal compositional distributions, and we assume that the mean compositions of these sample sets are accurate representations of the chemistry of the regolith and the regolith's parent granite. At sites T2364 and T1755, however, a subset of the rock samples at each site has a quartz-rich composition that deviates strongly from the composition of the other rock samples at these sites and from the composition of rock samples at the other sites on Tailholt Mountain. Relative to typical rock samples on Tailholt Mountain, these anomalous rock samples have much lower concentrations of $\mathrm{Ca}, \mathrm{Sr}$, and $\mathrm{Na}$, among other elements (Figures S18-S19). In contrast to the bimodal rock samples at T2364 and T1755, the regolith samples at these sites fall into single unimodal distributions and have compositions similar to those in regoliths at the other Tailholt Mountain sites, suggesting they are derived from parent rocks similar to the parent rocks elsewhere on Tailholt Mountain. If we were to consider the average composition of all sampled rocks at sites T2364 and T1755-including the subsets of rock samples with anomalous compositionsto be representative of the parent material of the sampled regoliths, we would be forced into the geochemically unreasonable conclusion that highly soluble $\mathrm{Ca}$ and $\mathrm{Na}$ are much less chemically mobile than $\mathrm{Zr}$ at these sites. We therefore exclude the subsets of anomalous rock samples from all calculations of average rock composition at T2364 and T1755 and thus from calculations of chemical and physical erosion rates at these sites. A full list of the anomalous rock samples that were excluded as outliers at sites T2364 and T1755 is presented in the auxiliary materials.

\subsection{Chemical Composition in Regolith Profiles}

[26] In addition to the sixteen horizontally distributed regolith samples from $10-15 \mathrm{~cm}$ depths, we also measured the composition of regolith and underlying parent rock samples in a vertical profile at each site to assess vertical variability in composition. The site-averaged regolith thickness averages $40 \mathrm{~cm}$ and ranges from $16 \mathrm{~cm}$ to $>75 \mathrm{~cm}$ among sites. The absence of systematic vertical gradients in $\mathrm{Zr}$ or Ti concentrations within our sampled regolith profiles suggests either that negligible chemical weathering occurs within the regolith, or that the regolith is vertically mixed over the regolith residence time (Figure 3). The clear compositional difference between the regolith and the parent granite suggests that some chemical weathering indeed occurs in the regolith, and the presence of abundant rodent burrows in the regolith suggests that the regolith is indeed being mixed. Thus we infer that the sampled regoliths are generally well mixed.

[27] Not all 17 sites lack vertical trends in regolith immobile element concentrations; the regolith at site P1062S is an exception in this regard. For instance, concentrations of $\mathrm{Ti}$ at $\mathrm{P} 1062 \mathrm{~S}$ decrease systematically toward the surface from $0.56 \%$ at $60 \mathrm{~cm}$ depth to $0.37 \%$ at $5 \mathrm{~cm}$ depth. It is unclear why this site exhibits systematic vertical gradients in 


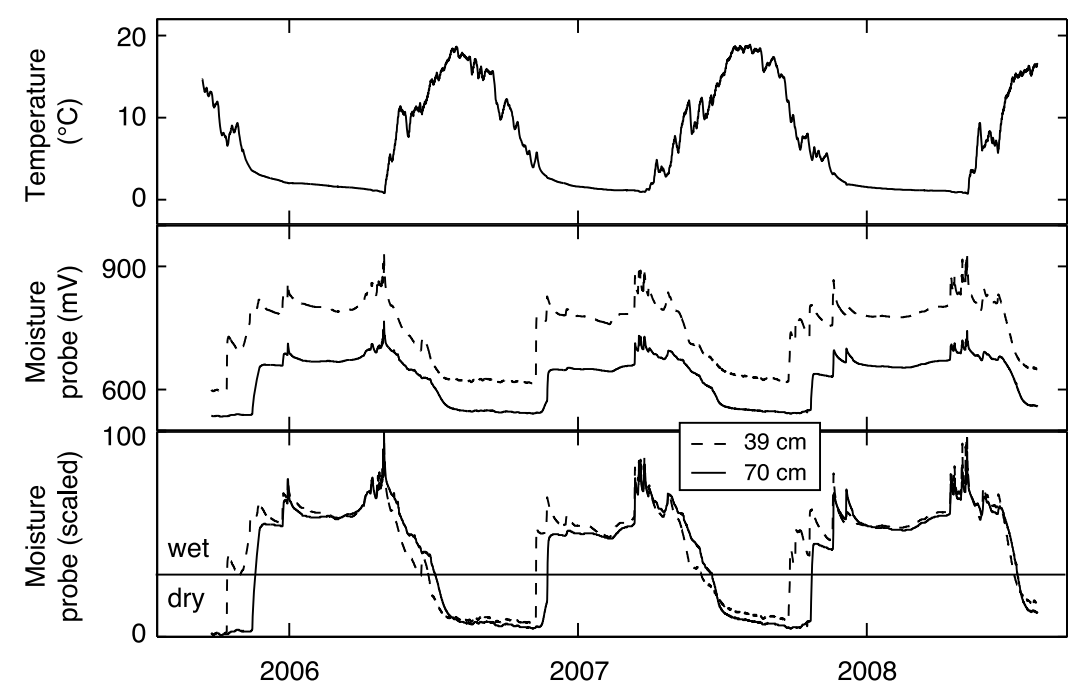

Figure 4. Daily average regolith temperature at the base of the regolith $(70 \mathrm{~cm}$ depth) and regolith moisture at depths of $39 \mathrm{~cm}$ (dashed line) and $70 \mathrm{~cm}$ (solid line) from a representative site (P2090S). In the middle panel are the raw measurements from the soil moisture probes. In the lower panel the same raw moisture probe time series have each been normalized to a $0-100$ scale, where 0 corresponds to the minimum (driest) reading and 100 to the maximum (wettest) reading over each time series. This scaling, although qualitative, greatly reduces offsets between regolith moisture records from different instruments in the same regolith profile, and permits simpler comparisons between regolith moisture records. Under this rescaling, the regolith in this figure spent on average $64 \%$ of each year in "wet" conditions, which we define as anything higher than an arbitrary threshold value of 30 in the rescaled regolith moisture data. The regolith climate time series for the other study sites are presented in the auxiliary materials.

regolith chemistry while the other sites do not, but our field observations suggest that the regolith at site P1062S was denser, less easily disaggregated, and had fewer animal burrows than the regoliths at the other study sites. These observations are consistent with little vertical mixing through most of the regolith at site P1062S, unlike the generally well-mixed regoliths observed at the other sites. We note that the upper two samples in the regolith profile at P1062S have compositions that are consistent with one another; for example, Ti concentrations are $0.38 \%$ at $12 \mathrm{~cm}$ depth and $0.37 \%$ at $5 \mathrm{~cm}$ depth. This suggests that this site's mean regolith composition-i.e., the average composition of the 16 horizontally distributed regolith samples at $10-15 \mathrm{~cm}$ depths - is indeed representative of the eroding regolith, which is what the geochemical mass balance requires.

\subsection{Regolith Climate Records}

[28] Instruments installed in the regolith at each site recorded temperature and a proxy for regolith moisture once every four hours from September 2005 to August 2008. These data were used to calculate mean annual regolith temperatures (MART) and regolith moisture indices (Table 2; Figure 5). These time series measurements show that at any given site, temperature and moisture in the regolith tend to be closely and inversely related to one another: regoliths are warm and dry during summers and cold and wet during winters (Figure 4). These measurements also show that regoliths at high altitudes are colder and have longer wet seasons than regoliths at low altitudes. Here we discuss the details of these measurements. 5.4.1. Regolith Temperature

[29] Figure 5 shows that MART broadly decreases with elevation on both Pilot Peak and Tailholt Mountain, as expected. The altitudinal gradients in MART, however, are only $2.2^{\circ} \mathrm{C} / \mathrm{km}$ on Tailholt Mountain and $3.1^{\circ} \mathrm{C} / \mathrm{km}$ on Pilot Peak, shallower than the altitudinal gradient in mean annual air temperature (MAAT) of $5^{\circ} \mathrm{C}-6^{\circ} \mathrm{C} / \mathrm{km}$ that would be expected from a standard moist atmospheric lapse rate. These low altitudinal gradients in MART are a result of a buffering of regolith temperatures near freezing during the winter months (e.g., Figure 4). We do not have time series measurements of snow depths at the study sites, but we speculate that the observed winter buffering of regolith temperatures may be a consequence of winter snow cover, which would insulate the regolith against cold excursions in air temperature. This temperature buffering is especially noticeable at the higher elevation sites (e.g., sites P2283S, $\mathrm{P} 2281 \mathrm{~N}$, and $\mathrm{T} 2364$ ), where the temperature drops to $2^{\circ} \mathrm{C}-$ $3^{\circ} \mathrm{C}$ in November and steadily decreases to $0 \pm 1^{\circ} \mathrm{C}$ over the course of the winter. At a few sites $(\mathrm{P} 1485 \mathrm{~N}, \mathrm{~T} 1755$, T1294), this winter-long temperature buffering occurs at somewhat lower temperatures $\left(-3^{\circ} \mathrm{C}\right.$ to $\left.-7^{\circ} \mathrm{C}\right)$. During this time period, diurnal variations in regolith temperature are small $\left(<0.1^{\circ} \mathrm{C}\right)$. The net result of this winter temperature buffering is to make the annual regolith temperature cycle look roughly like a sinusoid with the wintertime troughs truncated at a warmer temperature than they would otherwise descend to. Because this winter temperature buffering prevents regoliths from getting as cold as the air during the winter, every regolith that experiences this temperature buffering has a MART that is warmer than the local MAAT. And, because this winter temperature buffering lasts longest at the highest altitudes - as long as seven months at the highest Tailholt Mountain site (T2364), and as short as two months at the lowest Pilot Peak site (P1062S) - the 


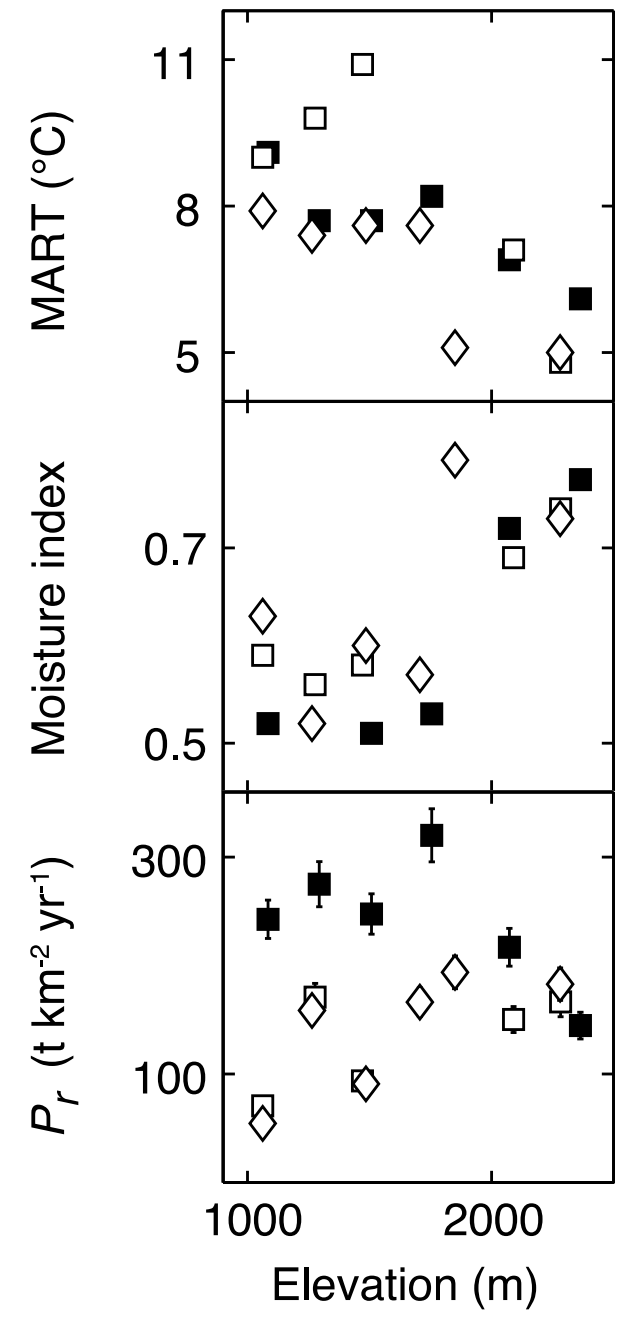

Figure 5. Upper panel: mean annual regolith temperatures (MART) on Pilot Peak (8/1/2006-7/31/2008; white markers) and Tailholt Mountain (10/1/2005-9/30/2006; black markers). On Pilot Peak, white diamonds refer to sites on the north side of the ridgeline, and white squares refer to sites on the south side. For the purposes of calculating annual means, some records include interpolations to fill gaps in temperature time series; see section S6 in the auxiliary materials for details. Middle panel: regolith moisture indices represent the fraction of the year the regolith spends in the "wet" condition (defined in Figure 4), and show that regoliths at higher elevations tend to spend a greater proportion of each year under high regolith moisture conditions. Figures S21-S37 in the auxiliary materials show the full time series from which MART and moisture indices were calculated. Lower panel: Regolith production rates $P_{r}$ inferred from cosmogenic ${ }^{10} \mathrm{Be}$ in regolith-borne quartz (mean $\pm \mathrm{SE}$ ). Aside from site T2364, regolith production rates are faster on Tailholt Mountain than on Pilot Peak. On Pilot Peak, regolith production rates on opposite sides of the ridgeline at the same elevation are identical within uncertainty, implying that climatic factors related to slope aspect are not affecting bedrock lowering rates at these sites. difference between MART and MAAT is bigger at higher altitudes than at lower altitudes. This results in altitudinal gradients in MART that are shallower than the expected altitudinal gradient in MAAT of $5^{\circ} \mathrm{C}-6^{\circ} \mathrm{C} / \mathrm{km}$.

[30] As well as being a function of altitude, regolith temperatures at these field sites also depend on slope aspect and vegetation. South-facing slopes are systematically hotter by $1{ }^{\circ} \mathrm{C}-3^{\circ} \mathrm{C}$ MART than north-facing slopes at the same altitude (compare sites P1471S and P1485N, P1277S and $\mathrm{P} 1264 \mathrm{~N}$, and P1062S and P1062N in Table 2). The exception to this pattern is at the highest elevation sites on Pilot Peak, where the south facing site P2283S has regoliths that are slightly cooler than those at site P2281N on the north side of the ridgeline. This is likely a consequence of differences in vegetation between P2283S and P2281N. Uniquely among all of our field sites on both mountains, site P2283S lies under a thick grove of conifers and is well shaded from the sun. By contrast, site P2281N is vegetated only with bunch grasses and is exposed directly to the sun. Thus we attribute the cooler regolith temperatures at $\mathrm{P} 2283 \mathrm{~S}$ relative to those at $\mathrm{P} 2281 \mathrm{~N}$ to vegetative shading at $\mathrm{P} 2283 \mathrm{~S}$.

\subsubsection{Regolith Moisture}

[31] We found it impossible to accurately calibrate the raw capacitance measurements from the soil moisture probes. Raw measurements from multiple moisture probes in a single regolith profile often show similar temporal patternsthat is, they show spikes and troughs in the measured voltage at similar times - but they also show significant offsets from one another (Figure 4), which precluded the use of a single calibration curve for all moisture probes. Instead of attempting to determine absolute regolith moisture contents from each moisture probe, we used the probes' raw capacitance measurements to quantify the duration of the wet season at each site, reasoning that relative changes in capacitance measured by a single probe should still reflect the relative changes in regolith moisture around that probe over time. To make more direct (albeit more qualitative) comparisons between records from different soil moisture probes, we rescaled the time series of voltages measured by each moisture probe on a $0-100$ scale, such that the minimum (i.e., driest) voltage recorded by each instrument over its entire time series is rescaled to 0 , and the maximum (i.e., wettest) voltage over its time series is rescaled to 100 . Rescaling each record in this manner resolves much of the offset between records.

[32] When rescaled in this manner, regolith moisture records reveal that the wet season tends to last longer at higher elevations than at low elevations. This can be crudely quantified as follows. Consider a regolith moisture time series that has been rescaled to a 0-100 scale (e.g., Figure 4). The transitions between the wet and dry seasons are short relative to the duration of the wet and dry seasons themselves, and thus to first order regolith moisture is either high or low at any given moment during this time series. In each of the rescaled regolith moisture records we defined any measurement above an arbitrary threshold of 30 as "wet" and any measurement below this threshold as "dry", a threshold that effectively separates dry summer conditions from wet winter conditions in regolith at each of the study sites. We then characterized each site in terms of the annual duration of wet conditions (expressed as a fraction of the year), and called this fraction the Moisture Index. The 
Table 4. Results of the Dust-Granite Mixing Model Mass Balance ${ }^{\mathrm{a}}$

\begin{tabular}{|c|c|c|c|c|c|}
\hline Site Name & $f_{d}(\%)^{\mathrm{b}}$ & $\mathrm{CDF}^{\mathrm{c}}$ & $P_{d}\left(\mathrm{t} \mathrm{km}^{-2} \mathrm{yr}^{-1}\right)^{\mathrm{d}}$ & $E\left(\mathrm{t} \mathrm{km}^{-2} \mathrm{yr}^{-1}\right)^{\mathrm{e}}$ & $W\left(\mathrm{t} \mathrm{km}^{-2} \mathrm{yr}^{-1}\right)^{\mathrm{e}}$ \\
\hline \multicolumn{6}{|c|}{ Pilot Peak } \\
\hline P2283S & $2.7 \pm 1.0$ & $0.15 \pm 0.02$ & $5 \pm 2$ & $145 \pm 13$ & $26 \pm 4$ \\
\hline P2281N & $6.1 \pm 1.4$ & $0.14 \pm 0.02$ & $12 \pm 3$ & $167 \pm 15$ & $28 \pm 5$ \\
\hline P2090S & $7.7 \pm 1.5$ & $0.14 \pm 0.03$ & $13 \pm 3$ & $141 \pm 13$ & $22 \pm 5$ \\
\hline $\mathrm{P} 1850 \mathrm{~N}$ & $4.7 \pm 1.5$ & $-0.04 \pm 0.04$ & $8 \pm 3$ & $210 \pm 19$ & $-9 \pm 8$ \\
\hline P1850Nsub ${ }^{f}$ & $4.0 \pm 1.2$ & $0.04 \pm 0.03$ & $9 \pm 3$ & $194 \pm 17$ & $9 \pm 7$ \\
\hline $\mathrm{P} 1706 \mathrm{~N}$ & $5.4 \pm 1.3$ & $0.07 \pm 0.03$ & $10 \pm 3$ & $163 \pm 14$ & $12 \pm 5$ \\
\hline $\mathrm{P} 1485 \mathrm{~N}$ & $7.0 \pm 1.2$ & $0.13 \pm 0.02$ & $7 \pm 1$ & $85 \pm 7$ & $13 \pm 2$ \\
\hline P1471S & $2.8 \pm 0.7$ & $0.08 \pm 0.02$ & $3 \pm 1$ & $89 \pm 7$ & $8 \pm 2$ \\
\hline P1277S & $-2.7 \pm 0.8$ & $0.10 \pm 0.03$ & $-5 \pm 1$ & $149 \pm 12$ & $17 \pm 6$ \\
\hline P1264N & $3.1 \pm 1.0$ & $0.05 \pm 0.03$ & $5 \pm 2$ & $155 \pm 13$ & $9 \pm 6$ \\
\hline P1062S & $6.5 \pm 1.3$ & $0.15 \pm 0.02$ & $5 \pm 1$ & $64 \pm 5$ & $12 \pm 2$ \\
\hline P1062N & $13.9 \pm 2.2$ & $0.16 \pm 0.01$ & $9 \pm 2$ & $53 \pm 4$ & $10 \pm 1$ \\
\hline \multicolumn{6}{|c|}{ Tailholt Mountain } \\
\hline T2364 & $5.1 \pm 1.1$ & $0.15 \pm 0.03$ & $8 \pm 2$ & $130 \pm 14$ & $22 \pm 5$ \\
\hline T2073 & $2.9 \pm 0.7$ & $0.04 \pm 0.02$ & $7 \pm 2$ & $215 \pm 18$ & $8 \pm 4$ \\
\hline T1755 & $3.6 \pm 0.7$ & $-0.02 \pm 0.02$ & $12 \pm 3$ & $338 \pm 27$ & $-6 \pm 8$ \\
\hline T1508 & $3.6 \pm 0.8$ & $0.02 \pm 0.03$ & $9 \pm 2$ & $252 \pm 21$ & $5 \pm 7$ \\
\hline T1294 & $1.5 \pm 0.7$ & $0.13 \pm 0.03$ & $4 \pm 2$ & $242 \pm 21$ & $37 \pm 9$ \\
\hline T1084 & $3.1 \pm 0.7$ & $0.11 \pm 0.02$ & $8 \pm 2$ & $224 \pm 17$ & $27 \pm 5$ \\
\hline
\end{tabular}

\footnotetext{
${ }^{\mathrm{a}}$ All uncertainties listed in this table are standard errors.
}

${ }^{\mathrm{b}}$ The fraction of the regolith's parent material derived from dust, $f_{d}$, was estimated in [Ferrier et al., 2011], under the assumption that the regolith composition is a mixture of the sampled granite and mafic dust from Columbia Plateau paleoflood sediments [Sweeney et al., 2007].

${ }^{c}$ Estimates of $\mathrm{CDF}$ are calculated as the fraction of the total regolith denudation rate that is attributable to chemical processes (equation (6)).

${ }^{\mathrm{d}}$ Estimates of dust incorporation rate $P_{d}$ from [Ferrier et al., 2011].

${ }^{\text {e}}$ Physical and chemical erosion rates $E$ and $W$ are calculated with equations (3) and (4), respectively.

${ }^{\mathrm{f}} \mathrm{P} 1850 \mathrm{Nsub}$ results are calculated using a subset of regolith samples at site P1850N (see section 6.3).

regolith in Figure 4, for example, spent on average 64\% of the year in the "wet" state, and thus had a Moisture Index of 0.64 . When the same analysis is repeated on all regolith moisture records, it shows that the lowest elevation sites spent about half the year in the "wet" state and the highest elevation sites spent about three-quarters of the year in the "wet" state (Figure 5). Although this is an unsophisticated analysis of uncalibrated data, it nonetheless illustrates a fundamental aspect of this mountain system: high altitude regoliths tend to spend a higher proportion of the time "wet" than low altitude sites do. We speculate that this may be a consequence of the winter snow cover, which lasts longer at higher altitudes and which we expect to promote high regolith moisture levels while it lasts.

\subsection{Dust Incorporation Into Regolith}

[33] As discussed in [Ferrier et al., 2011], two characteristics of rock-to-regolith elemental enrichments across the study sites suggest that regolith compositions have been affected by incorporation of mafic dust. First, at all of the study sites except one (P1277S), rock-to-regolith enrichments of $\mathrm{Ti}$ are considerably higher than those of $\mathrm{Zr}$. In the absence of Ti-rich dust incorporation into the soil, such a systematic discrepancy would be inconsistent with the probable chemical immobility of both $\mathrm{Zr}$ and Ti. Second, rock-to-regolith enrichments of other elements that are usually considered to be mobile - especially $\mathrm{Mn}$ and $\mathrm{Fe}$, and to a lesser extent $\mathrm{Mg}$ - are higher than those for presumably immobile $\mathrm{Zr}$ at many sites. In the absence of direct measurements of dust incorporation rate and dust composition in the South Fork of the Salmon River canyon, Ferrier et al. [2011] estimated the long-term average dust incorporation rate at each site using the local regolith production rate; concentrations of $\mathrm{Zr}$ and $\mathrm{Ti}$ in regolith, rock, and dust; and the composition of a probable dust source (the glacial megaflood sediments that produced the nearby Palouse loess) [Sweeney et al., 2007; this study, Table S6]. Here we use those estimates of dust composition and dust incorporation rates to help estimate chemical and physical erosion rates with equations (3)-(5) at the study sites on Pilot Peak and Tailholt Mountain.

\section{Chemical Erosion Rates, Regolith Chemical Depletion, and Climate}

\subsection{Bulk Chemical Erosion Rates and Chemical Depletion Fractions}

[34] Using our measurements of regolith production rates (Table 3), the compositions of regolith, rock, and dust (Tables S3-S6), and our estimates of dust incorporation rates (Table 4) [Ferrier et al., 2011], we calculate the bulk chemical erosion rate $(W)$ and the chemical depletion fraction (CDF) at each site with equations (4) and (6). Reported uncertainties on values of $W$ and CDF are one standard error of the mean, calculated by propagating uncertainties on all parameters in equations (4) and (6) - i.e., uncertainties in $P_{r}, P_{d}$, and the compositions of rock, dust, and regolith.

[35] We note that the calculated rates pertain to mass fluxes out of the regolith, and do not include chemical mass fluxes that may be occurring at depths greater than a few meters below the surface. That is, if some mass were lost below the depth of cosmogenic ${ }^{10} \mathrm{Be}$ accumulation (e.g., by chemical weathering at depths greater than a few meters), then our measurements would not be able to detect those deep mass losses, and the calculated values of $E$ and $W$ would reflect the mass fluxes in the regolith but not those at depth [Dixon et al., 2009a]. Therefore we interpret the calculated chemical and physical erosion rates as mass fluxes 


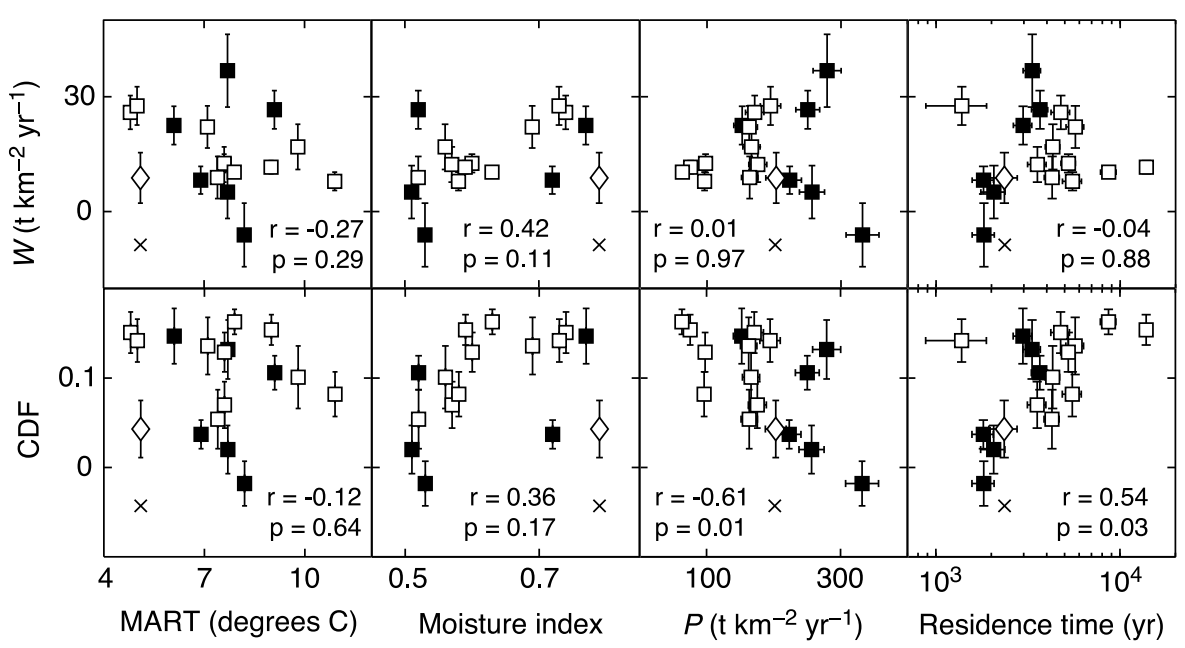

Figure 6. Chemical erosion rates $(W)$ and chemical depletion fractions (CDF) plotted against mean annual regolith temperature (MART), moisture index (defined in Figure 4), mineral supply rates $P$, and regolith residence times. White symbols $=$ Pilot Peak; black symbols $=$ Tailholt Mountain; $r=$ correlation coefficient; $p=p$-value for $r$. The white diamond and the $\times$ symbol represent site $\mathrm{P} 1850 \mathrm{~N}$ excluding and including anomalous regolith samples, respectively (section 6.3). Estimates of $W$ do not increase with MART, suggesting that mean annual regolith temperature exerts little influence on bulk chemical erosion rates at these field sites. Estimates of $W$ generally increase with moisture index, particularly on Pilot Peak, suggesting that the annual duration of high regolith moisture conditions promotes chemical erosion. Estimates of $W$ do not increase linearly with the rate of mineral supply $P$ and show little dependence on regolith residence times, implying that chemical erosion rates at these sites are not supply-limited. Estimates of CDF-i.e., the degree of chemical alteration in the regolith — show no trend with MART, and broadly increase with the moisture index. Estimates of CDF decrease with mineral supply rate and increase with regolith residence time on both Pilot Peak and Tailholt Mountain, consistent with chemical erosion that is limited by the kinetics of mineral dissolution rather than the rate of fresh mineral supply to the regoliths. All values are means \pm one standard error.

from the regolith, and note that if significant chemical erosion were occurring at depths greater than a few meters, total chemical erosion rates from the weathering profile would be higher than the calculated $W$ values. This interpretation differs from studies that have taken rock outcrops to be chemical proxies for pristine bedrock, and which have interpreted chemical erosion rates calculated with equation (4) as a reflection of total chemical mass fluxes, including fluxes that may be occurring below the regolith [e.g., Riebe et al., 2004a]. Future measurements of $\mathrm{Zr}$ concentrations in deep bedrock profiles will be required to determine whether deep chemical weathering fluxes are in fact significant at the study sites.

[36] As noted in section 2, these calculations implicitly assume that $\mathrm{Zr}$ is immobile in the sampled regoliths, which we suggest is appropriate at the study sites because $\mathrm{Zr}$ in granites is found predominantly in zircons, which are highly resistant to dissolution [e.g., Hodson, 2002]. If $\mathrm{Zr}$ were mobile within the regolith (e.g., due to density differences between zircons and the bulk regolith) [Taboada et al., 2006], then the inferred chemical erosion rates and CDFs would be lower than their true values to the extent that regolith $\mathrm{Zr}$ concentrations were lower than what they would be if $\mathrm{Zr}$ were perfectly immobile. Under the assumption of $\mathrm{Zr}$ immobility, our calculations show that physical erosion is responsible for $84 \%-100 \%$ of the mass flux out of the sampled regoliths and that chemical erosion accounts for the remaining $0 \%-16 \%$.
[37] These calculations reveal that chemical erosion rates on Pilot Peak are fastest at the highest altitudes, where regoliths are coldest and where regolith moisture levels remain high for the longest portion of the year. Chemical erosion rates on Tailholt Mountain, by contrast, reach a minimum at an intermediate altitude and are of comparable magnitude at the top and bottom of the altitudinal transect. Plotting these rates against climatic variables permits us to make several observations about the influence of climate on chemical erosion rates and the extent of chemical alteration in these regoliths.

[38] First, chemical erosion rates do not increase with mean annual regolith temperature (MART) (see Figure 6). Because chemical erosion rates are expected to increase with temperature, all else being equal [e.g., White and Blum, 1995], this suggests that the regoliths at our field sites are only weakly sensitive to MART, if at all. To the extent that temperature influences chemical erosion rates along these transects, its influence is overwhelmed by the influences of other factors.

[39] Second, our measurements are suggestive of a weak correlation between chemical erosion rates and moisture index (Figure 6). That is, chemical erosion rates tend to be higher at higher moisture indices, although the correlation between chemical erosion rates and moisture index is not statistically significant at a high level $(p=0.11)$. For example, the mean $W$ at sites with moisture indices $>0.65$ is $19 \mathrm{t}$ $\mathrm{km}^{-2} \mathrm{yr}^{-1}$, while the mean $W$ at sites with moisture indices 

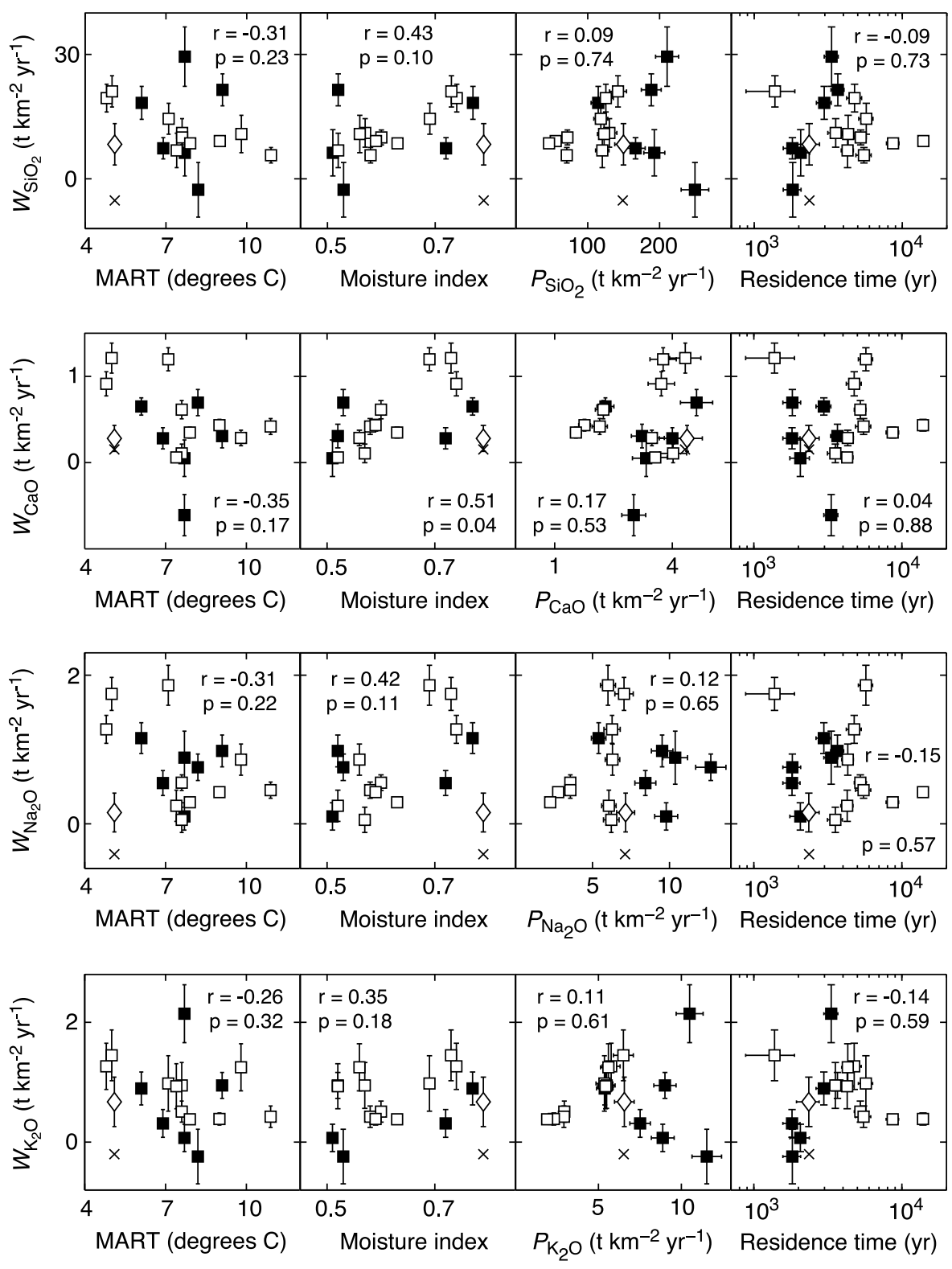

Figure 7. Elemental chemical erosion rates $W_{X}$ plotted against mean annual regolith temperature (MART), moisture index (defined in Figure 4), elemental supply rates $P_{X}$, and regolith residence times. White symbols $=$ Pilot Peak; black symbols $=$ Tailholt Mountain; $\mathrm{r}=$ correlation coefficient; $p=p$-value for $r$. The white diamond and the $\times$ symbol represent site P1850N excluding and including anomalous regolith samples, respectively (section 6.3). All values are means \pm one standard error.

$<0.65$ is $11 \mathrm{t} \mathrm{km}^{-2} \mathrm{yr}^{-1}$. Thus these data do not support a strong dependence of $W$ on moisture index, but they are suggestive of a weak link between the length of the annual wet season and millennial-scale chemical erosion rates.

[40] Two further observations can be made by normalizing the chemical erosion rates by the rate of material supply to the regolith. This reveals that the degree of regolith chemical alteration (i.e., the CDF) is insensitive to MART, just as chemical erosion rates in regolith are insensitive to MART (Figure 6). By contrast, the extent of chemical weathering appears to be more sensitive to variations in soil moisture; the most weathered regoliths at our field sites tend to be at the sites with the longest wet seasons (Figure 6). This is the clearest climatic signal in our measurements.

\subsection{Elemental Chemical Erosion Rates and Chemical Depletion Fractions}

[41] The same estimates of regolith production rates, dust incorporation rates, and rock, regolith, and dust composition (Tables 3-4; Tables S3-S6 in the auxiliary materials) permit calculation of elemental chemical erosion rates $W_{X}$ with equation (5). As expected, chemical erosion rates for $\mathrm{SiO}_{2}$ are by far the largest among any oxide, reflecting the dominance of $\mathrm{Si}$ in the parent material contributing to the regoliths (Figure 7). Chemical erosion rates for $\mathrm{Al}_{2} \mathrm{O}_{3}$ are the next largest elemental chemical weathering flux, followed in size by the chemical erosion rates of the major cations $\mathrm{K}$, $\mathrm{Na}$, and $\mathrm{Ca}$. The chemical erosion of $\mathrm{Al}$ from regolith at our 
Table 5. Means $\pm \mathrm{SE}$ of $\mathrm{CDF}_{X}$ (unitless) and $W_{X}\left(\mathrm{t} \mathrm{km}^{-2} \mathrm{yr}^{-1}\right)$ Calculated With Equations (5) and (7)

\begin{tabular}{|c|c|c|c|c|c|c|c|}
\hline Site & $\mathrm{CDF}_{A l}$ & $\mathrm{CDF}_{\mathrm{Ca}}$ & $\mathrm{CDF}_{F e}$ & $\mathrm{CDF}_{K}$ & $\mathrm{CDF}_{M g}$ & $\mathrm{CDF}_{N a}$ & $\mathrm{CDF}_{S i}$ \\
\hline \multicolumn{8}{|c|}{ Pilot Peak } \\
\hline P2283S & $0.11 \pm 0.03$ & $0.25 \pm 0.03$ & $0.02 \pm 0.01$ & $0.22 \pm 0.06$ & $0.27 \pm 0.02$ & $0.20 \pm 0.02$ & $0.16 \pm 0.02$ \\
\hline P2281N & $0.08 \pm 0.03$ & $0.28 \pm 0.02$ & $-0.01 \pm 0.02$ & $0.22 \pm 0.05$ & $0.08 \pm 0.03$ & $0.25 \pm 0.02$ & $0.15 \pm 0.02$ \\
\hline P2090S & $0.14 \pm 0.04$ & $0.32 \pm 0.02$ & $0.07 \pm 0.02$ & $0.18 \pm 0.08$ & $0.14 \pm 0.03$ & $0.31 \pm 0.03$ & $0.12 \pm 0.03$ \\
\hline $\mathrm{P} 1850 \mathrm{~N}$ & $-0.09 \pm 0.04$ & $0.04 \pm 0.03$ & $-0.05 \pm 0.02$ & $-0.03 \pm 0.07$ & $0.10 \pm 0.03$ & $-0.06 \pm 0.04$ & $-0.04 \pm 0.04$ \\
\hline P1850Nsub ${ }^{a}$ & $-0.02 \pm 0.04$ & $0.06 \pm 0.03$ & $-0.02 \pm 0.03$ & $0.10 \pm 0.06$ & $0.11 \pm 0.04$ & $0.02 \pm 0.04$ & $0.06 \pm 0.03$ \\
\hline $\mathrm{P} 1706 \mathrm{~N}$ & $0.00 \pm 0.03$ & $0.03 \pm 0.03$ & $-0.01 \pm 0.02$ & $0.17 \pm 0.06$ & $0.09 \pm 0.03$ & $0.01 \pm 0.03$ & $0.09 \pm 0.03$ \\
\hline $\mathrm{P} 1485 \mathrm{~N}$ & $0.05 \pm 0.03$ & $0.27 \pm 0.03$ & $0.02 \pm 0.02$ & $0.17 \pm 0.05$ & $0.30 \pm 0.02$ & $0.16 \pm 0.03$ & $0.14 \pm 0.02$ \\
\hline P1471S & $0.05 \pm 0.03$ & $0.20 \pm 0.03$ & $0.00 \pm 0.01$ & $0.15 \pm 0.05$ & $0.25 \pm 0.02$ & $0.13 \pm 0.03$ & $0.08 \pm 0.03$ \\
\hline P1277S & $0.13 \pm 0.03$ & $0.08 \pm 0.02$ & $0.16 \pm 0.02$ & $0.22 \pm 0.06$ & $0.14 \pm 0.04$ & $0.14 \pm 0.03$ & $0.09 \pm 0.04$ \\
\hline $\mathrm{P} 1264 \mathrm{~N}$ & $0.03 \pm 0.04$ & $0.02 \pm 0.01$ & $0.00 \pm 0.02$ & $0.17 \pm 0.06$ & $0.10 \pm 0.03$ & $0.04 \pm 0.03$ & $0.06 \pm 0.03$ \\
\hline P1062S & $0.10 \pm 0.02$ & $0.25 \pm 0.03$ & $0.08 \pm 0.03$ & $0.17 \pm 0.04$ & $0.22 \pm 0.03$ & $0.15 \pm 0.02$ & $0.16 \pm 0.02$ \\
\hline P1062N & $0.06 \pm 0.02$ & $0.23 \pm 0.03$ & $0.09 \pm 0.02$ & $0.20 \pm 0.03$ & $0.27 \pm 0.03$ & $0.13 \pm 0.01$ & $0.19 \pm 0.01$ \\
\hline \multicolumn{8}{|c|}{ Tailholt Mountain } \\
\hline T2364 & $0.07 \pm 0.04$ & $0.28 \pm 0.03$ & $-0.03 \pm 0.03$ & $0.17 \pm 0.04$ & $-0.01 \pm 0.05$ & $0.21 \pm 0.03$ & $0.16 \pm 0.03$ \\
\hline $\mathrm{T} 2073$ & $-0.01 \pm 0.02$ & $0.07 \pm 0.03$ & $-0.02 \pm 0.02$ & $0.04 \pm 0.03$ & $0.08 \pm 0.03$ & $0.07 \pm 0.02$ & $0.04 \pm 0.01$ \\
\hline $\mathrm{T} 1755$ & $-0.09 \pm 0.03$ & $0.15 \pm 0.03$ & $-0.03 \pm 0.03$ & $-0.02 \pm 0.04$ & $0.15 \pm 0.05$ & $0.06 \pm 0.01$ & $-0.01 \pm 0.03$ \\
\hline $\mathrm{T} 1508$ & $-0.03 \pm 0.02$ & $0.02 \pm 0.06$ & $-0.06 \pm 0.02$ & $0.01 \pm 0.02$ & $0.02 \pm 0.04$ & $0.01 \pm 0.02$ & $0.03 \pm 0.03$ \\
\hline T1294 & $0.13 \pm 0.03$ & $-0.20 \pm 0.09$ & $-0.08 \pm 0.03$ & $0.20 \pm 0.04$ & $0.05 \pm 0.05$ & $0.09 \pm 0.03$ & $0.14 \pm 0.03$ \\
\hline T1084 & $0.08 \pm 0.02$ & $0.10 \pm 0.04$ & $0.03 \pm 0.02$ & $0.10 \pm 0.02$ & $0.16 \pm 0.03$ & $0.10 \pm 0.02$ & $0.11 \pm 0.02$ \\
\hline Site & $W_{\mathrm{Al}_{2} \mathrm{O}_{3}}$ & $W_{\mathrm{CaO}}$ & $W_{\mathrm{Fe}_{2} \mathrm{O}_{3}}$ & $W_{K_{2} O}$ & $W_{M g O}$ & $W_{\mathrm{Na}_{2} \mathrm{O}}$ & $W_{\mathrm{SiO}_{2}}$ \\
\hline \multicolumn{8}{|c|}{ Pilot Peak } \\
\hline P2283S & $2.8 \pm 0.8$ & $0.9 \pm 0.1$ & $0.08 \pm 0.06$ & $1.3 \pm 0.4$ & $0.23 \pm 0.03$ & $1.3 \pm 0.2$ & $19 \pm 3$ \\
\hline P2281N & $2.3 \pm 0.9$ & $1.2 \pm 0.2$ & $-0.05 \pm 0.11$ & $1.4 \pm 0.4$ & $0.08 \pm 0.05$ & $1.7 \pm 0.2$ & $21 \pm 4$ \\
\hline P2090S & $3.4 \pm 1.1$ & $1.2 \pm 0.1$ & $0.22 \pm 0.11$ & $1.0 \pm 0.5$ & $0.14 \pm 0.05$ & $1.9 \pm 0.3$ & $14 \pm 4$ \\
\hline $\mathrm{P} 1850 \mathrm{~N}$ & $-2.8 \pm 1.2$ & $0.2 \pm 0.2$ & $-0.19 \pm 0.10$ & $-0.2 \pm 0.4$ & $0.10 \pm 0.04$ & $-0.4 \pm 0.3$ & $-5 \pm 6$ \\
\hline P1850Nsub ${ }^{a}$ & $-0.6 \pm 0.3$ & $0.3 \pm 0.2$ & $-0.07 \pm 0.12$ & $0.7 \pm 0.4$ & $0.10 \pm 0.05$ & $0.2 \pm 0.3$ & $8 \pm 5$ \\
\hline $\mathrm{P} 1706 \mathrm{~N}$ & $0.1 \pm 0.8$ & $0.1 \pm 0.1$ & $-0.04 \pm 0.08$ & $0.9 \pm 0.4$ & $0.07 \pm 0.03$ & $0.1 \pm 0.2$ & $11 \pm 3$ \\
\hline $\mathrm{P} 1485 \mathrm{~N}$ & $0.8 \pm 0.4$ & $0.6 \pm 0.1$ & $0.03 \pm 0.05$ & $0.5 \pm 0.2$ & $0.17 \pm 0.03$ & $0.6 \pm 0.1$ & $10 \pm 2$ \\
\hline P1471S & $0.8 \pm 0.4$ & $0.4 \pm 0.1$ & $0.00 \pm 0.03$ & $0.4 \pm 0.2$ & $0.12 \pm 0.02$ & $0.5 \pm 0.1$ & $6 \pm 2$ \\
\hline P1277S & $3.2 \pm 0.9$ & $0.3 \pm 0.1$ & $0.36 \pm 0.06$ & $1.2 \pm 0.4$ & $0.08 \pm 0.03$ & $0.9 \pm 0.2$ & $11 \pm 5$ \\
\hline $\mathrm{P} 1264 \mathrm{~N}$ & $0.8 \pm 0.9$ & $0.1 \pm 0.1$ & $-0.01 \pm 0.06$ & $0.9 \pm 0.4$ & $0.07 \pm 0.03$ & $0.2 \pm 0.2$ & $7 \pm 4$ \\
\hline P1062S & $1.1 \pm 0.3$ & $0.4 \pm 0.1$ & $0.12 \pm 0.05$ & $0.4 \pm 0.1$ & $0.09 \pm 0.02$ & $0.4 \pm 0.1$ & $9 \pm 1$ \\
\hline P1062N & $0.5 \pm 0.2$ & $0.3 \pm 0.1$ & $0.13 \pm 0.07$ & $0.4 \pm 0.1$ & $0.12 \pm 0.03$ & $0.3 \pm 0.04$ & $9 \pm 1$ \\
\hline \multicolumn{8}{|c|}{ Tailholt Mountain } \\
\hline T2364 & $1.6 \pm 0.9$ & $0.7 \pm 0.1$ & $-0.06 \pm 0.07$ & $0.9 \pm 0.3$ & $-0.01 \pm 0.03$ & $1.2 \pm 0.2$ & $18 \pm 4$ \\
\hline T2073 & $-0.2 \pm 0.7$ & $0.3 \pm 0.1$ & $-0.06 \pm 0.06$ & $0.3 \pm 0.2$ & $0.06 \pm 0.02$ & $0.5 \pm 0.2$ & $7 \pm 3$ \\
\hline $\mathrm{T} 1755$ & $-4.5 \pm 1.3$ & $0.7 \pm 0.2$ & $-0.12 \pm 0.13$ & $-0.2 \pm 0.5$ & $0.12 \pm 0.06$ & $0.8 \pm 0.2$ & $-3 \pm 7$ \\
\hline T1508 & $-1.1 \pm 0.9$ & $0.1 \pm 0.2$ & $-0.20 \pm 0.09$ & $0.1 \pm 0.2$ & $0.01 \pm 0.04$ & $0.1 \pm 0.2$ & $6 \pm 6$ \\
\hline T1294 & $5.2 \pm 1.5$ & $-0.6 \pm 0.2$ & $-0.23 \pm 0.08$ & $2.1 \pm 0.5$ & $0.03 \pm 0.03$ & $0.9 \pm 0.4$ & $29 \pm 7$ \\
\hline $\mathrm{T} 1084$ & $2.8 \pm 0.8$ & $0.3 \pm 0.1$ & $0.10 \pm 0.07$ & $0.9 \pm 0.2$ & $0.09 \pm 0.03$ & $1.0 \pm 0.2$ & $21 \pm 4$ \\
\hline
\end{tabular}

${ }^{\mathrm{a}} \mathrm{P} 1850$ Nsub values calculated using a subset of regolith samples at site P1850N (section 6.3).

study sites is consistent with measurements of Al losses from regolith at a number of other sites [e.g., White et al., 1998; Chadwick et al., 2003; Green et al., 2006], implying that chemical erosion of $\mathrm{Al}$ is often responsible for a substantial fraction of the solute mass flux from regolith. This picture of chemical mobility of $\mathrm{Al}$ in regolith contrasts with the traditional view of chemical immobility of $\mathrm{Al}$ in streams, which is supported by observations of fluvial solute fluxes of Al that are 20-500 times smaller than fluvial solute fluxes of major cations $\mathrm{Ca}, \mathrm{Mg}, \mathrm{K}$, and $\mathrm{Na}$ in granitic terrain (e.g., [Garrels and Mackenzie, 1967]). Resolving the widely observed discrepancy between chemical fluxes of $\mathrm{Al}$ in regolith and streams is beyond the scope of this project, but we note that it will require investigating the mechanisms of Al weathering and transport through substantially weathered regolith profiles.

[42] Patterns in $\mathrm{W}_{\mathrm{SiO}_{2}}$ with MART and moisture index at our study sites tend to mimic the patterns in bulk chemical erosion rates $W$ on both mountains (Figure 7). This is expected; at most of our field sites $W_{\mathrm{SiO}_{2}}$ constitutes $64 \%-95 \%$ of the bulk chemical erosion rate, so patterns in $W$ should largely reflect patterns in $W_{\mathrm{SiO}_{2}}$. As is the case with bulk chemical erosion rates, elemental chemical erosion rates do not increase with MART for any major element (Figure 7). Similarly, on Pilot Peak $W_{\mathrm{Na}_{2} \mathrm{O}}, W_{\mathrm{CaO}}$, and $W_{\mathrm{SiO}_{2}}$ broadly mimic the bulk chemical erosion rate in that they are generally fastest at the highest moisture indices (Figure 7). Because $\mathrm{Na}$ and $\mathrm{Ca}$ are probably derived primarily from the plagioclase feldspar that dominates the parent granite, we infer that these patterns in $W_{\mathrm{Na}_{2} \mathrm{O}}$ and $W_{\mathrm{CaO}}$ likely reflect plagioclase weathering. The similarity of the patterns in $W_{\mathrm{SiO}_{2}}$ to those in $W_{\mathrm{Na}_{2} \mathrm{O}}$ and $W_{\mathrm{CaO}}$ suggests that chemical erosion of $\mathrm{Si}$ is likely dominated by plagioclase weathering as well.

[43] Elemental depletion factors $\left(C D F_{X}\right.$; Table 5) have patterns that are broadly similar to those in the bulk $C D F$. Estimates of $C D F_{X}$ show no strong trends with MART for any major element, and are suggestive of a weak correlation with moisture index for $\mathrm{Ca}, \mathrm{Na}$, and $\mathrm{Si}$ (Figure 8). That is, 

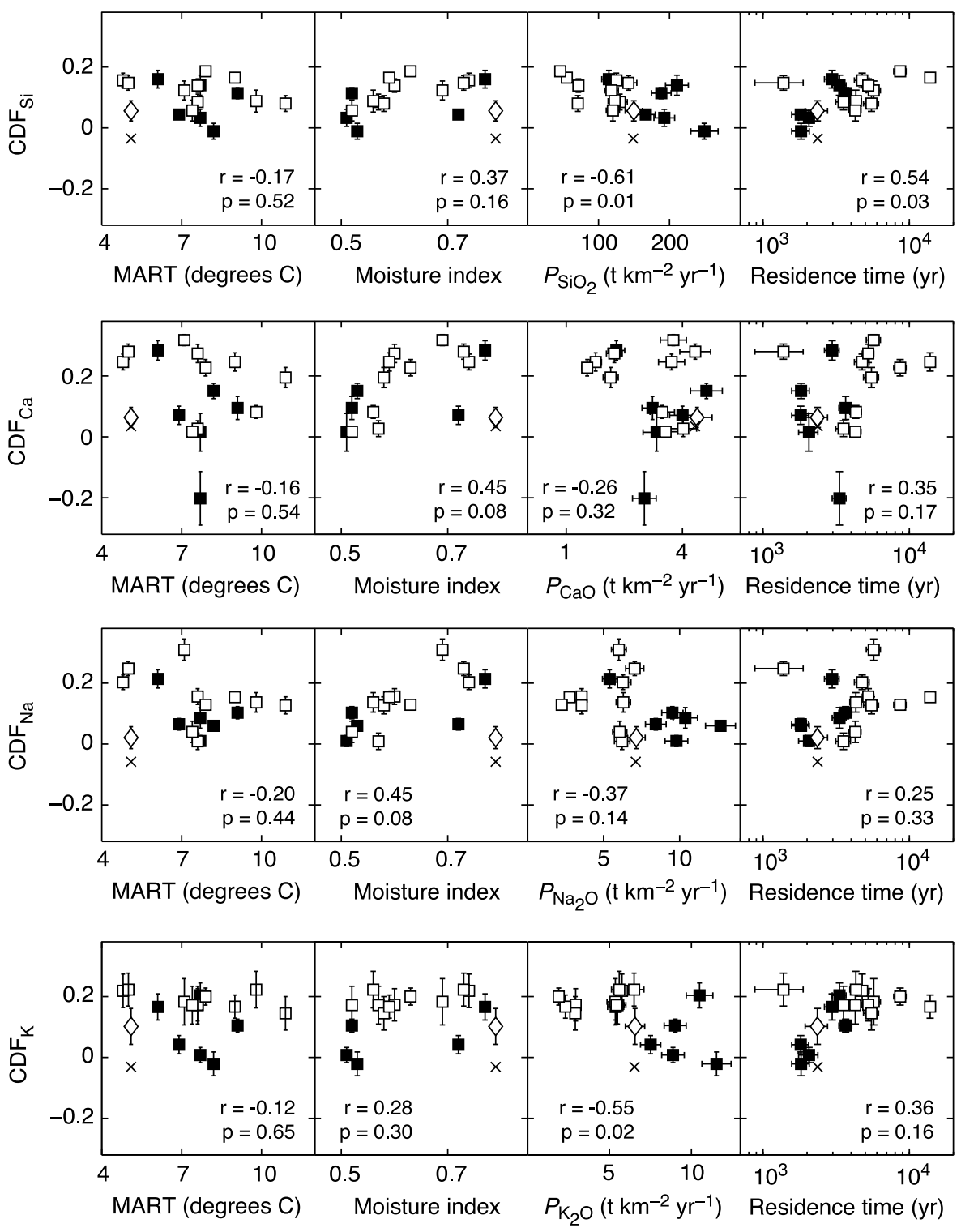

Figure 8. Elemental chemical depletion fractions $\mathrm{CDF}_{X}$ plotted against mean annual regolith temperature (MART), moisture index (defined in Figure 4), elemental supply rates $P_{X}$, and regolith residence times. White symbols $=$ Pilot Peak; black symbols $=$ Tailholt Mountain; $\mathrm{r}=$ correlation coefficient; $p=p$-value for $r$. The white diamond and the $\times$ symbol represent site P1850N excluding and including anomalous regolith samples, respectively (section 6.3). All values are means \pm one standard error.

$C D F_{C a}, C D F_{N a}$, and $C D F_{S i}$ are not strongly correlated with moisture index at a high significance level, but each tends to be higher at higher moisture indices. For instance, the correlation between $C D F_{N a}$ and moisture index has a $p$-value of 0.08 , but the study sites with moisture indices $>0.65$ have a mean $C D F_{N a}$ of 0.18 , while the sites with moisture indices $<0.65$ have a mean $C D F_{N a}$ of 0.11 . This is consistent with weathering of plagioclase feldspar that has progressed farthest in regoliths with the longest wet seasons.

[44] In summary, at these field sites chemical erosion rates and the degree of chemical depletion in the regolith show little to no dependence on mean annual regolith temperature, both for the bulk regolith and for individual elements. By contrast, rates of chemical erosion and the degree of chemical depletion are positively correlated with the length of the wet season, particularly for $\mathrm{Ca}$ and $\mathrm{Na}$, and to a lesser extent for $\mathrm{Si}$. We note, however, that any effects of temperature on $W, W_{X}, C D F$, and $C D F_{X}$ may be masked by the covariance of moisture index and temperature across the study sites. That is, because MART and moisture index are inversely correlated across the study sites (Figure 5), the influence of MART on chemical erosion rates and CDFs may be counteracted by the influences of moisture index on chemical erosion rates and CDFs, to the extent that higher MART and higher moisture indices both promote faster chemical erosion and higher CDFs.

\subsection{Anomalous Regolith Compositions at Two Sites}

[45] Two field sites on Pilot Peak do not fit the assumptions underlying the solid-phase mass balance method for 
estimating chemical erosion rates, as Table 4 shows. The first is site P1277S. As noted in [Ferrier et al., 2011], this is the only site on either Pilot Peak or Tailholt Mountain where the rock-to-regolith enrichment of $\mathrm{Ti}$ is smaller than that of $\mathrm{Zr}$. As a result, the addition of dust with a higher Ti/Zr ratio than the parent granite cannot resolve the differences between rock-to-regolith enrichments of $\mathrm{Zr}$ and $\mathrm{Ti}$ at $\mathrm{P} 1277 \mathrm{~S}$, as it can at the other sixteen sites. It is not immediately clear why P1277S differs from the other sites in this regard. However, we note that although the rock sample composition at P1277S is not unusual for rocks from Pilot Peak, the P1277S regolith samples have more $\mathrm{Si}$ and less $\mathrm{Al}, \mathrm{Fe}, \mathrm{Ti}, \mathrm{Mg}, \mathrm{Nb}$, and $\mathrm{Rb}$ than the other Pilot Peak regoliths. We suggest that the rock samples collected from the ridgeline between sites P1277S and P1264N may be a poor reflection of the parent granite that produced the regolith at site P1277S.

[46] Site P1850N is the other site that yields an anomalous result, although for a different reason than at P1277S. At $\mathrm{P} 1850 \mathrm{~N}$ the rock and regolith compositions are consistent with the addition of mafic-rich dust, but the estimated bulk CDF is below zero, which in turn results in a negative chemical erosion rate, which is an impossibility. This odd result occurs at $\mathrm{P} 1850 \mathrm{~N}$ because some of the $\mathrm{P} 1850 \mathrm{~N}$ regolith samples have a much different composition than the others. The rectangular plot from which regoliths were sampled at P1850N lies just a few meters off the north-facing side of the ridgeline, and ten of the sixteen regolith samples - all in the western half of the regolith plot, and at the same elevation as the remaining six regolith samples in the eastern half of the regolith plot-are much rockier than the other regolith samples, and have lower $\mathrm{Zr}$ concentrations than the other $\mathrm{P} 1850 \mathrm{~N}$ regoliths and the bulk of the P1850N rock samples. Meanwhile, in the eastern half of the regolith plot just a few meters away, the other P1850N regolith samples have a composition much closer to that of the sampled P1850N rocks. To show how much excluding the regolith samples in the western half of the sampling plot affects the calculated regolith composition at $\mathrm{P} 1850 \mathrm{~N}$, in Figures 6-8 we present two sets of values for $W, W_{X}, \mathrm{CDF}$, and $\mathrm{CDF}_{X}$ at $\mathrm{P} 1850 \mathrm{~N}$ : one set calculated from the average composition of all regolith samples, and a second set calculated from the average composition of the subset of regolith samples from the eastern half of the regolith plot (i.e., samples P1850N-B5, B6, B9, B10, B13, B14). Figures 6-8 reveal that excluding the anomalously rocky regolith samples in the western half of the sampling plot yields values for chemical erosion rates that are no longer negative. These data demonstrate that large variations in regolith composition can exist parallel to topographic contours - i.e., variations unrelated to chemical erosion that may progress during downslope regolith transport — and can strongly influence calculated values for $W$ and CDF. As such these measurements highlight the importance of collecting multiple regolith samples along topographic contours when quantifying mean hillslope regolith composition.

[47] We also note that although using the proposed dust source within the dust-granite mixing model helps resolve most of the unexpected granite-to-regolith elemental enrichments, it does not resolve all of them. In particular, after including dust influxes from the proposed dust source, several $\mathrm{CDF}_{F e}$ on Tailholt Mountain are still negative (although they are much less negative than they would have been if dust had been neglected; Table 5). This may indicate that the dust falling on these sites had a higher Fe concentration than the proposed dust source. Elevated concentrations of Fe in dust relative to the dust source can result from compositional sorting during transport, as Fe may be preferentially sited in small secondary Fe-oxide mineral grains that are more likely to be transported long distances [e.g., Jickells et al., 2005]. Future measurements of dust composition in the South Fork of the Salmon River canyon will be needed to test this hypothesis.

\subsection{Climate in Central Idaho Over Annual and Millennial Timescales}

[48] There is a large difference in timescale between the annual-scale regolith climate measurements and the millennial-scale chemical erosion rate measurements, as there is in any study that attempts to link modern climatic time series to long-term processes of regolith development. Central Idaho's climate has not been invariant over the course of regolith development at the study sites, so here we frame the modern regolith climate measurements in a longer-term context. Before doing so, however, we point out that a fundamental strength of altitudinal transect studies (including this one) is their robustness against changes in regional climate, because they rely on the climatic differences between the study sites, and these will not be substantially altered by regional climate shifts. That is, changes in regional climate will have little effect on how temperature and precipitation vary with altitude (i.e., the lapse rates), or on how insolation varies with aspect; these are the factors that create the climate differences among the study sites. Thus climate changes would not substantially alter the site-to-site climatic differences on which our analysis is based.

[49] Longer-term contexts for our regolith climate measurements can be found in 20th century weather station data and Holocene pollen records. The closest weather station to the study sites is $15 \mathrm{~km}$ northwest of Pilot Peak in Warren, Idaho (http://www.wrcc.dri.edu/cgi-bin/cliMAIN.pl?id9560, accessed March 2011). Relative to its 35-year mean, mean annual air temperature at Warren was $0.87^{\circ} \mathrm{C}$ warmer during 10/1/2005-9/30/2006 (the year for which we have complete regolith monitoring records at all sites on Tailholt Mountain) and $0.65^{\circ} \mathrm{C}$ warmer during 8/1/2006-7/31/2008 (the two years for which we have complete regolith monitoring records at all sites on Pilot Peak). Mean annual precipitation at Warren was $63 \mathrm{~cm}$ during 10/1/2005-9/30/2006 and $53 \mathrm{~cm}$ during $8 / 1 / 2006-7 / 31 / 2008$, both drier than the 32-year mean of $69 \mathrm{~cm}$.

[50] Regolith residence times at the study sites range from $1.4 \mathrm{kyr}$ to $13.9 \mathrm{kyr}$, which are, of course, much longer than the climate records at nearby monitoring stations. We are unaware of quantitative constraints on temperature and moisture over millennial timescales in central Idaho, but qualitative constraints on millennial-scale changes in climate can be found from nearby paleoecology studies. The closest study of this type is from McCall Fen, $35 \mathrm{~km}$ west-southwest of Tailholt Mountain [Doerner and Carrara, 2001]. Radiocarbon dating and analysis of pollen grains in a sediment core imply a climate that was, relative to present conditions, cold and dry from $19.6 \mathrm{ka}$ until $14.0 \mathrm{ka}$; cool and moist from $14.0 \mathrm{ka}$ to $11.2 \mathrm{ka}$; warm and dry from 11.2 to $3.4 \mathrm{ka}$; and cool and moist from $3.4 \mathrm{ka}$ to the present (all ages are calibrated years BP). This is broadly similar to paleoclimate histories 
inferred from other pollen records in the region. [Doerner and Carrara, 1999] interpreted pollen in sediment cores 55-70 km southwest of Tailholt Mountain as implying conditions that were, relative to the present climate, warm and dry from $11.2 \mathrm{ka}$ to $3.4 \mathrm{ka}$ and cool and moist after $3.4 \mathrm{ka}$. [Whitlock et al., 2011] interpreted pollen in a sediment core $125 \mathrm{~km}$ south-southeast of Tailholt Mountain as a reflection of conditions that were, relative to present conditions, warmer and drier from $8.24 \mathrm{ka}$ to $2.65 \mathrm{ka}$, with a transition to a climate supporting the modern forest composition by $2.65 \mathrm{ka}$. [Brunelle et al., 2005] interpreted pollen records from sediment cores $75-150 \mathrm{~km}$ northeast of Pilot Peak as reflecting mid-Holocene conditions that were warmer and/or drier than the present, followed by a shift to a cooler and wetter climate by 3 ka.

[51] Although the changes in climate inferred from these pollen records are not perfectly synchronous with one another, they are consistent with a mid-Holocene warm period that was preceded and followed by cooler and wetter climates. Thus, if the pollen records in central Idaho are representative of regolith climate at the study sites, then during the monitoring period the sampled regoliths may have been warmer and drier than they were over the past $\sim 3 \mathrm{kyr}$ and cooler and wetter than they were before $\sim 3 \mathrm{ka}$. As we suggest above, however, such fluctuations in regional climate over the Holocene should have had little effect on climatic differences among the study sites, which is the relevant factor for our analysis. Furthermore, regoliths at five of the 17 sample sites have residence times $<3 \mathrm{kyr}$, which implies those regoliths developed under climatic conditions similar to the present. Of the regoliths at the other twelve sites, only two have residence times $>5.8 \mathrm{kyr}$, which implies all but two of the sampled regoliths developed mainly under the present climate regime.

\section{Evidence for Kinetically-Limited Weathering}

[52] Chemical erosion of the bulk regolith and of elements within the regolith is often described as occurring in one of two end-member regimes: supply-limited or kinetically-limited [e.g., Stallard, 1983; West, 2005]. In supply-limited weathering, chemical erosion rates are limited by the rate at which fresh material is supplied to the regolith. For the bulk regolith, this supply rate is the total mass flux into the regolith $P$, and in the case of an element $X$, this supply rate is $P_{X}$ (equations (1)-(2)). In the supply-limited weathering regime, chemical erosion rates are linearly proportional to supply rates, and the degree of chemical depletion in the regolith-i.e., the $\mathrm{CDF}$ - is constant across a range of regolith production rates and is independent of the regolith residence time. In its simplest and most extreme form, supply-limited weathering of a given element occurs where $100 \%$ of that element is lost by chemical processes because it is present only in highly soluble minerals which themselves undergo complete weathering. This has been observed, for example, in tropical weathering profiles where $100 \%$ of the $\mathrm{Na}$ in the parent rock is lost by complete weathering of plagioclase feldspar, which is the sole host of Na in the parent rock [e.g., White et al., 1998]. In such a scenario $W_{N a}=P_{N a}$ and $\mathrm{CDF}_{N a}=1$. Direct proportionalities between chemical erosion rates and supply rates can also arise in settings where weathering is less extreme (i.e., where the $\mathrm{CDF}<1$ ). Consider, for example, a rock in which element $X$ is hosted by several different mineral phases, some of which are highly soluble and some of which are insoluble. If, during weathering of this rock, element $X$ were completely lost from the soluble minerals and completely retained by the insoluble minerals, regardless of supply rate, this would yield a $\mathrm{CDF}_{X}$ with a value less than 1 that is constant across all supply rates. Close correlations between chemical erosion rates and supply rates have been observed over a wide range of field sites where measured CDFs are much lower than 1 [Riebe et al., 2004a; Dixon et al., 2009a]. These studies suggest that supply-limited weathering appears to be a useful descriptor of chemical erosion at these sites, in that it can account for a great deal of the measured variance in chemical erosion rates between sites. In contrast to supply-limited weathering, kinetically-limited weathering is characterized by chemical erosion rates that are limited not by the rate of fresh mineral supply but by how slowly the minerals themselves weather. In this regime, chemical erosion rates are less than linearly proportional to regolith production rates, and regoliths grow more chemically depleted (i.e., the CDF increases) with regolith residence time.

[53] At our field sites on Pilot Peak and Tailholt Mountain it appears that the bulk regolith and most of the elements are experiencing kinetically-limited weathering. Estimates of the bulk CDF in regolith systematically decrease with supply rate and increase with regolith residence time, consistent with chemical erosion that is limited by the kinetics of mineral dissolution rather than the rate of fresh mineral supply (Figure 6). (Here regolith residence time is calculated as the regolith thickness times regolith density divided by the mass influx rate $P$, where regolith density is assumed to be $1640 \mathrm{~kg} \mathrm{~m}^{-3}$ at each site based on the dry density of regolith collected on Pilot Peak and measured in the lab.) This pattern is especially clear on Tailholt Mountain, which has one cluster of CDFs near zero at short regolith residence times ( $<2500$ years) and a second cluster of CDFs at $0.11-0.15$ at longer regolith residence times ( $>2500$ years). On Pilot Peak, by contrast, many but not all of the data are consistent with a rising trend in $\mathrm{CDF}$ with regolith residence time. The Pilot Peak sites with the smallest CDFs tend to cluster at the shortest regolith residence times, but CDFs do not increase continuously with regolith residence time over all Pilot Peak sites. The sites with the two longest regolith residence times (P1062S and P1062N) have CDFs of $0.15 \pm 0.02$ and $0.16 \pm 0.01$, respectively, identical within uncertainty to CDFs at other sites on Pilot Peak with considerably shorter residence times.

[54] Although most of the elemental $\mathrm{CDF}_{X}$ measurements are broadly similar to the bulk CDF measurements-i.e., the smallest values of $\mathrm{CDF}_{X}$ for each element tend to cluster at the shortest regolith residence times, consistent with kinetically-limited weathering - there is one notable exception to this general pattern, and that is $\mathrm{CDF}_{K}$ at Pilot Peak. Aside from the unusual site $\mathrm{P} 1850 \mathrm{~N}$ (see section 6.3), all values of $\mathrm{CDF}_{K}$ on Pilot Peak are the same within uncertainty, and imply that roughly $20 \%$ of the K supplied to the regolith leaves in solution across a wide range of regolith residence times (Figure 8). As a result, $W_{K}$ on Pilot Peak is linearly proportional to the rate at which $\mathrm{K}$ is supplied to the regolith, consistent with supply-limited chemical erosion of K on Pilot Peak (Figure 7). It may be that $20 \%$ of the $\mathrm{K}$ in the parent material is in easily weatherable minerals (e.g., biotite) and the other $80 \%$ is in less soluble minerals 
(e.g., K-feldspar), and that to first order all of the $\mathrm{K}$ in easily weatherable minerals and none of the $\mathrm{K}$ in other minerals is lost during a single regolith residence time. Future work on the quantitative mineralogy of the parent material and the elemental distributions within the parent minerals will be needed to shed light on the pathways of elemental weathering in this system, and will be needed to test hypotheses for the cause of supply-limited weathering behavior displayed by $\mathrm{K}$ on Pilot Peak and the cause of kinetically-limited weathering behavior displayed by other elements and the bulk regolith.

[55] In summary, our data broadly support the notion that chemical erosion of the bulk regolith and of most elements in the regolith is proceeding at rates that are limited by the kinetics of mineral dissolution, rather than the supply rates of minerals to the regolith.

\section{Conclusions}

[56] In this paper we have presented new measurements of regolith production rates, regolith and rock chemistry, and regolith climate along two altitudinal transects in the Idaho Batholith. Several observations about the dependence of chemical erosion rates on climate and supply rates can be gleaned from these data. First, chemical erosion rates at these field sites do not increase with mean annual regolith temperature, contrary to the relationship predicted by theory and laboratory experiments. Second, chemical erosion rates show a weak tendency to be faster in regoliths with higher moisture indices (i.e., in regoliths with longer wet seasons). Third, chemical erosion rates do not increase proportionally with the rate of fresh mineral supply. Fourth, the degree of chemical alteration (i.e., the CDF) is positively correlated with the moisture index: regoliths that spend more time each year under high regolith moisture conditions are more weathered. Fifth, estimates of CDF decrease with the mineral supply rate and increase with the regolith residence time: regoliths that spend more time on the hillslope are more weathered.

[57] We draw two main conclusions from these observations. First, the data suggest that chemical erosion rates in the study regoliths are largely insensitive to temperature, although we cannot rule out the possibility that chemical erosion rates may have a temperature dependence that is masked by a dependence on the length of the wet season, which covaries inversely with temperature across the study sites. The lack of a positive correlation between chemical erosion rates and temperature in the study regoliths is consistent with a number of studies that have also shown weak climatic controls on chemical erosion rates over decadal and millennial timescales [Dupre et al., 2003; Riebe et al., 2004a; West et al., 2005], and they differ from studies that have inferred strong climatic signals in chemical erosion rates along altitudinal transects in Nevada [Riebe et al., 2004b] and the Sierra Nevada [Dixon et al., 2009a]. Second, we conclude that chemical erosion in the study regoliths is generally proceeding in a kinetically-limited regime - i.e., a regime in which the rate of chemical erosion is limited by how slowly mineral dissolution reactions proceed - rather than in a supply-limited regime. In this regard our measurements differ from those of [Riebe et al., 2004a], which displayed a close proportionality between chemical erosion rates and mineral supply rates across a wide array of field sites, and are similar to those of [Norton and von Blanckenburg, 2010], who interpreted measurements of denudation rates and CDFs in the Swiss Alps as evidence for kinetic control on chemical erosion rates.

[58] One possible interpretation for the absence of strong correlations between climate and chemical erosion rates at Pilot Peak and Tailholt Mountain is that temperature and moisture exert no more than weak influences on chemical erosion rates at these sites. Such a conclusion would be surprising, given that chemical erosion rates in the study regoliths are not strongly dependent on mineral supply rates and thus should be sensitive to factors like temperature and moisture that influence mineral dissolution kinetics. Another possible interpretation is that although Pilot Peak and Tailholt Mountain span considerable ranges in altitude $(1.5 \mathrm{~km}$ and $1.3 \mathrm{~km}$, respectively), such ranges are not large enough to generate large climatic effects on chemical erosion rates. For instance, large variations in chemical erosion rates along a $2.8 \mathrm{~km}$ altitudinal transect in the Sierra Nevada have been interpreted as a reflection of a lack of moisture at low altitudes and a lack of warmth at high altitudes [Dahlgren et al., 1997; Dixon et al., 2009b]. The altitudinal patterns in these studies, however, would have been less apparent if those studies had been conducted over an altitudinal range of only $1.2-1.3 \mathrm{~km}$, similar to the altitude range of our transects. A third possible explanation is that the study transects do not cross thresholds across which chemical erosion rates are especially sensitive to climate. For instance, Riebe et al. [2004b] found that chemical erosion rates dropped sharply above the tree line in an altitudinal transect in Nevada's Santa Rosa Mountains. The observations in [Riebe et al., 2004b] are consistent with the notion that biota are an important driver of mineral weathering, and thus that chemical erosion rates may be especially sensitive to climate in places where biotic species distributions change sharply with small changes in climate (e.g., the tree line). If true, this would suggest that altitudinal transects that lie entirely below the tree line (like Pilot Peak and Tailholt Mountain) may be less likely to exhibit strong covariations of chemical erosion rates with climate than altitudinal transects that straddle the tree line (like the Santa Rosa Mountains).

[59] Finally, the possibility remains that both temperature and moisture exert positive controls on chemical erosion rates at the study sites, but that their effects are masked by one another because temperature and moisture covary inversely among the study sites. The difficulty in deconvolving the effects of temperature and moisture suggests that there could be value in measuring chemical erosion rates at sites across which temperature varies widely while precipitation rates remain invariant (or vice versa). If chemical erosion rates in such a study were limited by mineral dissolution kinetics rather than mineral supply rates, such a study would be particularly well-suited to isolate the effects of a single climatic variable on chemical erosion rates, and thus could help untangle the general effects of climate on chemical erosion rates.

[60] Acknowledgments. This work was supported by NSF grant EAR-0643129, and K.L.F. was supported by a Lawrence Scholar Graduate Fellowship at Lawrence Livermore National Laboratory during this study. We thank Editor Alex Densmore, Associate Editor Simon Mudd, Jean Dixon, and two anonymous reviewers for feedback that substantially 
improved this manuscript, and Cliff Riebe for many insightful discussions. We are also grateful to the U.S. Forest Service for assistance with field access; Michael Ferrier, Marisa Palucis, and Leslie Hsu for field assistance; and Tim Teague, Ajay Limaye, Shreya Ramesh, Greg Nishimura, and Evan Kha for laboratory assistance.

\section{References}

Anderson, S. P., W. E. Dietrich, and G. H. Brimhall (2002), Weathering profiles, mass-balance analysis, and rates of solute loss: Linkages between weathering and erosion in a small, steep catchment, Geol. Soc. Am. Bull., 114(9), 1143-1158.

Balco, G., J. O. Stone, N. A. Lifton, and T. J. Dunai (2008), A complete and easily accessible means of calculating surface exposure ages or erosion rates from ${ }^{10} \mathrm{Be}$ and ${ }^{26} \mathrm{Al}$ measurements, Quat. Geochronol., 3, 174-195, doi:10.1016/j.quageo.2007.12.001.

Berner, R. A., A. C. Lasaga, and R. M. Garrels (1983), The carbonatesilicate geochemical cycle and its effect on atmospheric carbon dioxide over the past 100 million years, Am. J. Sci., 283(7), 641-683.

Blum, A. E., and L. L. Stillings (1995), Feldspar dissolution kinetics, Rev. Mineral., 31, 291-352.

Bluth, G. S., and L. R. Kump (1994), Lithologic and climatic controls of river chemistry, Geochim. Cosmochim. Acta, 58(10), 2341-2359.

Bockheim, J. G., J. S. Munroe, D. Douglass, and D. Koerner (2000), Soil development along an elevational gradient in the southeastern Uinta Mountains, Utah, USA, Catena, 39, 169-185.

Brady, P. V., and S. A. Carroll (1994), Direct effects of $\mathrm{CO}_{2}$ and temperature on silicate weathering: Possible implications for climate control, Geochim. Cosmochim. Acta, 58(8), 1853-1856.

Brantley, S. L., H. Buss, M. Lebedeva, R. C. Fletcher, and L. Ma (2011), Investigating the complex interface where bedrock transforms to regolith, Appl. Geochem., 26, S12-S15, doi:10.1016/j.apgeochem.2011.03.017.

Brimhall, G. H., and W. E. Dietrich (1987), Constitutive mass balance relations between chemical composition, volume, density, porosity, and strain in metasomatic hydrochemical systems: Results on weathering and pedogenesis, Geochim. Cosmochim. Acta, 51(3), 567-587.

Brunelle, A., C. Whitlock, P. Bartlein, and K. Kipfmueller (2005), Holocene fire and vegetation along environmental gradients in the northern rocky mountains, Quat. Sci. Rev., 24, 2281-2300, doi:10.1016/j.quascirev.2004.11.010.

Burke, B. C., A. M. Heimsath, and A. F. White (2007), Coupling chemical weathering with soil production across soil-mantled landscapes, Earth Surf. Processes Landforms, 32(6), 853-873, doi:10.1002/esp.1443.

Burke, B. C., A. M. Heimsath, J. L. Dixon, J. Chappell, and K. Yoo (2009), Weathering the escarpment: Chemical and physical rates and processes, south-eastern Australia, Earth Surf. Processes Landforms, 34, 768-785, doi:10.1002/esp. 1764 .

Chadwick, O. A., G. H. Brimhall, and D. M. Hendricks (1990), From a black to a gray box-A mass balance interpretation of pedogenesis, Geomorphology, 3, 369-390.

Chadwick, O. A., R. T. Gavenda, E. F. Kelly, K. Ziegler, C. G. Olson, W. C. Elliott, and D. M. Hendricks (2003), The impact of climate on the biogeochemical functioning of volcanic soils, Chem. Geol., 202, 195-223.

Chen, Y., and S. L. Brantley (1997), Temperature- and pH-dependence of albite dissolution rate at acid pH, Chem. Geol., 135, 275-290.

Dahlgren, R. A., J. L. Boettinger, G. L. Huntington, and R. G. Amundson (1997), Soil development along an elevational transect in the western Sierra Nevada, California, Geoderma, 78, 207-236.

Dixon, J. L., A. M. Heimsath, and R. Amundson (2009a), The critical role of climate and saprolite weathering in landscape evolution, Earth Surf. Processes Landforms, 34, 1507-1521, doi:10.1002/esp.1836.

Dixon, J. L., A. M. Heimsath, and R. Amundson (2009b), Climate-driven processes of hillslope weathering, Geology, 37, 975-978, doi:10.1130/ G30045A.1.

Doerner, J. P., and P. E. Carrara (1999), Deglaciation and postglacial vegetation history of the West Mountains, west-central Idaho, U.S.A., Arct. Antarct. Alp. Res., 31, 303-311.

Doerner, J. P., and P. E. Carrara (2001), Late quaternary vegetation and climatic history of the Long Valley area, west-central Idaho, U.S.A., Quat. Res., 56, 103-111, doi:10.1006/qres.2001.2247.

Drever, J. I., and J. Zobrist (1992), Chemical weathering of silicate rocks as a function of elevation in the southern Swiss Alps, Geochim. Cosmochim. Acta, 56(8), 3209-3216.

Dupre, B., C. Dessert, P. Oliva, Y. Godderis, J. Viers, L. Francois, R. Millot, and J. Gaillardet (2003), Rivers, chemical weathering and Earth's climate, C. R. Geosci., 335, 1141-1160, doi:10.1016/j.crte.2003.09.015.

Egli, M., A. Mirabella, G. Sartori, and P. Fitze (2003), Weathering rates as a function of climate: Results from a climosequence of the Val Genova (Trentino, Italian Alps), Geoderma, 111, 99-121.
Egli, M., A. Mirabella, A. Mancabelli, and G. Sartori (2004), Weathering of soils in alpine areas as influenced by climate and parent material, Clays Clay Miner., 52(3), 287-303, doi:10.1346/CCMN.2004.0520304.

Egli, M., A. Mirabella, G. Sartori, R. Zanelli, and S. Bischof (2006), Effect of north and south exposure on weathering rates and clay mineral formation in Alpine soils, Catena, 67, 155-174, doi:10.1016/j.catena.2006.02.010.

Ferrier, K. L., J. W. Kirchner, and R. C. Finkel (2011), Estimating millennialscale rates of dust incorporation into eroding hillslope regolith using cosmogenic nuclides and immobile weathering tracers, J. Geophys. Res., 116, F03022, doi:10.1029/2011JF001991.

Gaillardet, J., B. Dupre, P. Louvat, and C. J. Allegre (1999), Global silicate weathering and $\mathrm{CO}_{2}$ consumption rates from the chemistry of large rivers, Chem. Geol., 159, 3-30.

Garrels, R. M., and F. T. Mackenzie (1967), Origin of the chemical compositions of some springs and lakes, Adv. Chem. Ser., 67, 222-242.

Gosse, J. C., and F. M. Phillips (2001), Terrestrial in situ cosmogenic nuclides: Theory and application, Quat. Sci. Rev., 20, 1475-1560.

Green, E. G., W. E. Dietrich, and J. F. Banfield (2006), Quantification of chemical weathering rates across an actively eroding hillslope, Earth Planet. Sci. Lett., 242, 155-169, doi:10.1016/j.epsl.2005.11.039.

Grieve, I. C., J. Proctor, and S. A. Cousins (1990), Soil variations with altitude on Volcan Barva, Costa Rica, Catena, 17, 525-534.

Heimsath, A. M., W. E. Dietrich, K. Nishiizumi, and R. C. Finkel (1997), The soil production function and landscape equilibrium, Nature, 388(6640), 358-361.

Hodson, M. E. (2002), Experimental evidence for mobility of $\mathrm{Zr}$ and other trace elements in soils, Geochim. Cosmochim. Acta, 66(5), 819-828.

Jickells, T. D., et al. (2005), Global iron connections between desert dust, ocean biogeochemistry, and climate, Science, 308, 67-71, doi:10.1126/ science. 1105959

Kirchner, J. W., R. C. Finkel, C. S. Riebe, D. E. Granger, J. L. Clayton, J. G. King, and W. F. Megahan (2001), Mountain erosion over $10 \mathrm{yr}$, 10 k.y., and 10 m.y. time scales, Geology, 29(7), 591-594.

Kohl, C. P., and K. Nishiizumi (1992), Chemical isolation of quartz for measurement of in situ-produced cosmogenic nuclides, Geochim. Cosmochim. Acta, 56(9), 3583-3587.

Kump, L. R., S. L. Brantley, and M. A. Arthur (2000), Chemical weathering, atmospheric $\mathrm{CO}_{2}$, and climate, Annu. Rev. Earth Planet. Sci., 28, 611-667.

Lebedeva, M. I., R. C. Fletcher, and S. L. Brantley (2010), A mathematical model for steady-state regolith production at constant erosion rate, Earth Surf. Processes Landforms, 35, 508-524, doi:10.1002/esp.1954.

Lund, K. (2004), Geology of the Payette National Forest and vicinity, westcentral Idaho, U.S. Geol. Surv. Prof. Pap., 1666-A-B, 97 pp., U.S. Geol Surv., Reston, Va.

Lund, K., L. W. Snee, and K. V. Evans (1986), Age and genesis of preciousmetals deposits, Buffalo Hump district, central Idaho: Implications for depth of emplacement of quartz veins, Econ. Geol., 81, 990-996, doi:10.2113/gsecongeo.81.4.990.

Millot, R., J. Gaillardet, B. Dupre, and C. J. Allegre (2002), The global control of silicate weathering rates and the coupling with physical erosion New insights from rivers of the Canadian Shield, Earth Planet. Sci. Lett., 196(1-2), 83-98.

Mudd, S. M., and D. J. Furbish (2006), Using chemical tracers in hillslope soils to estimate the importance of chemical denudation under conditions of downslope sediment transport, J. Geophys. Res., 111, F02021, doi:10.1029/2005JF000343.

Norton, K. P., and F. von Blanckenburg (2010), Silicate weathering of soilmantled slopes in an active alpine landscape, Geochim. Cosmochim. Acta, 74(18), 5243-5258, doi:10.1016/j.gca.2010.06.019.

Petit, J. R., et al. (1999), Climate and atmospheric history of the past 420,000 years from the Vostok ice core, Antarctica, Nature, 399, 429-436.

Rasmussen, C., S. Brantley, D. D. Richter, A. Blum, J. Dixon, and A. F. White (2011), Strong climate and tectonic control on plagioclase weathering in granitic terrain, Earth Planet. Sci. Lett., 301, 521-530, doi:10.1016/j.eps1.2010.11.037.

Riebe, C. S. (2000), Tectonic and climatic control of physical erosion rates and chemical weathering rates in the Sierra Nevada, California, inferred from cosmogenic nuclides and geochemical mass balance, Ph.D. thesis, Dep. of Earth and Planet. Sci., Univ. of Calif. Berkeley, Berkeley, Calif. Riebe, C. S., J. W. Kirchner, D. E. Granger, and R. C. Finkel (2001), Strong tectonic and weak climatic control of long-term chemical weathering rates, Geology, 29(6), 511-514.

Riebe, C. S., J. W. Kirchner, and R. C. Finkel (2003), Long-term rates of chemical weathering and physical erosion from cosmogenic nuclides and geochemical mass balance, Geochim. Cosmochim. Acta, 67(22), $4411-4427$.

Riebe, C. S., J. W. Kirchner, and R. C. Finkel (2004a), Erosional and climatic effects on long-term chemical weathering rates in granitic 
landscapes spanning diverse climate regimes, Earth Planet. Sci. Lett., 224(3-4), 547-562, doi:10.1016/j.epsl.2004.05.019.

Riebe, C. S., J. W. Kirchner, and R. C. Finkel (2004b), Sharp decrease in long-term chemical weathering rates along an altitudinal transect, Earth Planet. Sci. Lett., 218(3-4), 421-434, doi:10.1016/S0012-821X(03) 00673-3.

Stallard, R. F. (1985), River chemistry, geology, geomorphology, and soils in the Amazon and Orinoco basins, in The Chemistry of Weathering, edited by J. I. Drever, pp. 293-316, D. Reidel, Dordrecht, Netherlands.

Stallard, R. F., and J. M. Edmond (1983), Geochemistry of the Amazon 2. The influence of geology and weathering environment on the dissolved load J. Geophys. Res., 88(C14), 9671-9688, doi:10.1029/JC088iC14p09671.

Sweeney, M. R., D. R. Gaylord, and A. J. Busacca (2007), Evolution of Eureka Flat: A dust-producing engine of the Palouse loess, USA, Quat Int., 162-163, 76-96, doi:10.1016/j.quaint.2006.10.034.

Sweetkind, D. S., and D. D. Blackwell (1989), Fission-track evidence of the Cenozoic thermal history of the Idaho batholith, Tectonophysics, 157 241-250.

Taboada, T., A. M. Cortizas, C. García, and E. García-Rodeja (2006), Particle-size fractionation of titanium and zirconium during weathering and pedogenesis of granitic rocks in NW Spain, Geoderma, 131, 218-236, doi:10.1016/j.geoderma.2005.03.025

Velbel, M. A. (1993), Temperature dependence of silicate weathering in nature: How strong a negative feedback on long-term accumulation of atmospheric $\mathrm{CO}_{2}$ and global greenhouse warming?, Geology, 21 , 1059-1062.

Walker, J. C. G., P. B. Hays, and J. F. Kasting (1981), A negative feedback mechanism for the long-term stabilization of Earth's surface temperature, J. Geophys. Res., 86(C10), 9776-9782, doi:10.1029/JC086iC10p09776.
West, A. J., A. Galy, and M. Bickle (2005), Tectonic and climatic controls on silicate weathering, Earth Planet. Sci. Lett., 235, 211-228, doi:10.1016/j. eps1.2005.03.020

White, A. F., and A. E. Blum (1995), Effects of climate on chemical weathering in watersheds, Geochim. Cosmochim. Acta, 59(9), 1729-1747.

White, A. F., and S. L. Brantley (2003), The effect of time on the weathering of silicate minerals: Why do weathering rates differ in the laboratory and field?, Chem. Geol., 202(3-4), 479-506, doi:10.1016/j.chemgeo.2003.03.001.

White, A. F., A. E. Blum, M. S. Schulz, D. V. Vivit, D. A. Stonestrom, M. Larsen, S. F. Murphy, and D. Eberl (1998), Chemical weathering in a tropical watershed, Luquillo Mountains, Puerto Rico: I. Long-term versus short-term weathering fluxes, Geochim. Cosmochim. Acta, 62(2), 209-226.

White, A. F., A. E. Blum, T. D. Bullen, D. V. Vivit, M. Schulz, and J. Fitzpatrick (1999), The effect of temperature on experimental and natural chemical weathering rates of granitoid rocks, Geochim. Cosmochim. Acta, 63(19-20), 3277-3291.

Whitlock, C., C. E. Briles, M. C. Fernandez, and J. Gage (2011), Holocene vegetation, fire and climate history of the sawtooth range, central Idaho, USA, Quat. Res., 75, 114-124, doi:10.1006/j.yqres.2010.08.013.

Wilkinson, B. H., and B. J. McElroy (2007), The impact of humans on continental erosion and sedimentation, Geol. Soc. Am. Bull., 119(1/2), 140-156, doi:10.1130/B25899.

Yoo, K., and S. M. Mudd (2008), Discrepancy between mineral residence time and soil age: Implications for the interpretation of chemical weathering rates, Geology, 36(1), 35-38, doi:10.1130/G24285A.1.

Yoo, K., R. Amundson, A. M. Heimsath, W. E. Dietrich, and G. H. Brimhall (2007), Integration of geochemical mass balance with sediment transport to calculate rates of soil chemical weathering and transport on hillslopes, J. Geophys. Res., 112, F02013, doi:10.1029/2005JF000402. 